Review

\title{
Activated sludge characterization through microscopy: A review on quantitative image analysis and chemometric techniques
}

\author{
Daniela P. Mesquita ${ }^{a}$, A. Luís Amaral ${ }^{\mathrm{a}, \mathrm{b}}$, Eugénio C. Ferreira ${ }^{\mathrm{a}, *}$ \\ a IBB-Institute for Biotechnology and Bioengineering, Centre of Biological Engineering, Universidade do Minho, Campus de Gualtar, 4710-057 Braga, \\ Portugal \\ b Instituto Politécnico de Coimbra, ISEC, DEQB, Rua Pedro Nunes, Quinta da Nora, 3030-199 Coimbra, Portugal
}

\section{H I G H L I G H T S}

- Quantitative image analysis shows potential to monitor activated sludge systems.

- Staining techniques increase the potential for detection of operational problems.

- Chemometrics combined with quantitative image analysis is valuable for process monitoring.

\section{A R T I C L E I N F O}

\section{Article history:}

Received 10 June 2013

Received in revised form 5 September 2013

Accepted 7 September 2013

Available online 16 September 2013

\section{Keywords:}

Image analysis

Activated sludge

Aggregates

Filaments

Morphology

Chemometric techniques

\section{G R A P H I C A L A B S T R A C T}

\begin{abstract}
A B S T R A C T
In wastewater treatment processes, and particularly in activated sludge systems, efficiency is quite dependent on the operating conditions, and a number of problems may arise due to sludge structure and proliferation of specific microorganisms. In fact, bacterial communities and protozoa identification by microscopy inspection is already routinely employed in a considerable number of cases. Furthermore, quantitative image analysis techniques have been increasingly used throughout the years for the assessment of aggregates and filamentous bacteria properties. These procedures are able to provide an ever growing amount of data for wastewater treatment processes in which chemometric techniques can be a valuable tool. However, the determination of microbial communities' properties remains a current challenge in spite of the great diversity of microscopy techniques applied. In this review, activated sludge characterization is discussed highlighting the aggregates structure and filamentous bacteria determination by image analysis on bright-field, phase-contrast, and fluorescence microscopy. An in-depth analysis is performed to summarize the many new findings that have been obtained, and future developments for these biological processes are further discussed.
\end{abstract}

(C) 2013 Elsevier B.V. All rights reserved.

\section{Contents}

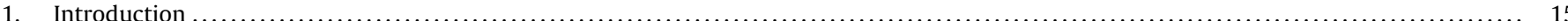

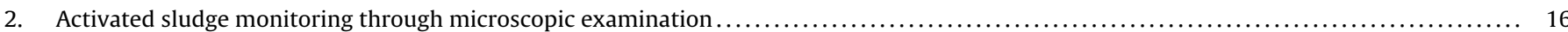

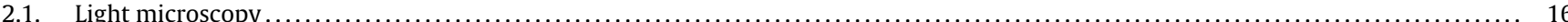

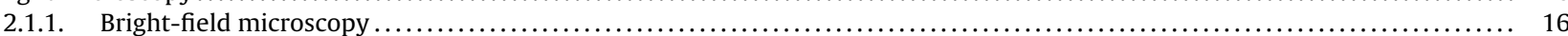

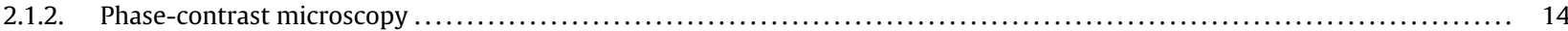

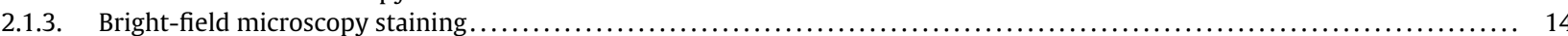

\footnotetext{
* Corresponding author. Tel.: +351253604 407; fax: +351253604 429.

E-mail address: ecferreira@deb.uminho.pt (E.C. Ferreira).
} 


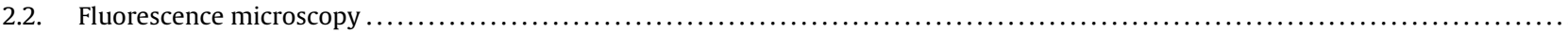

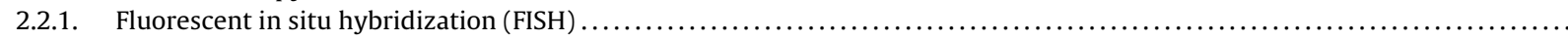

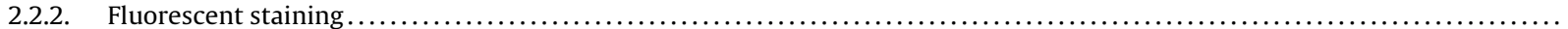

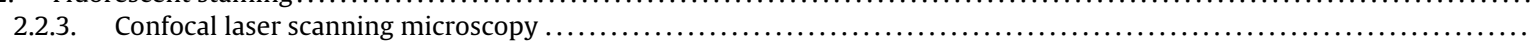

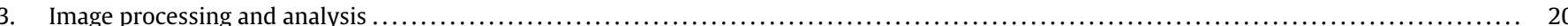

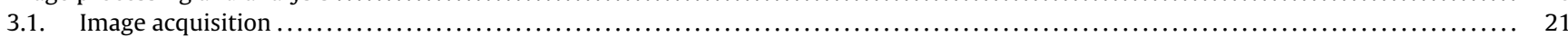

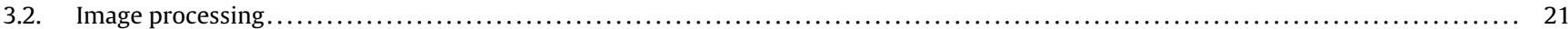

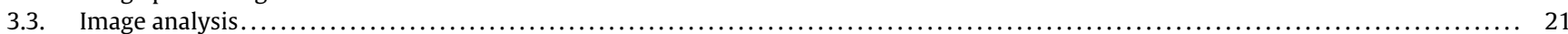

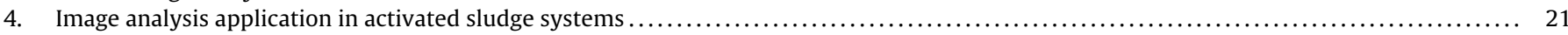

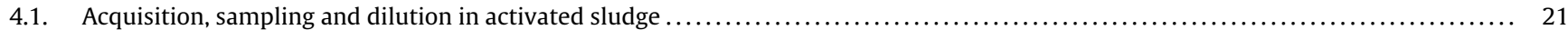

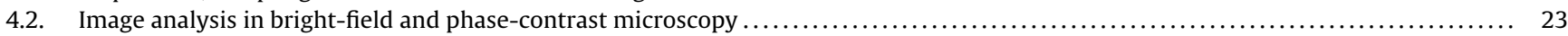

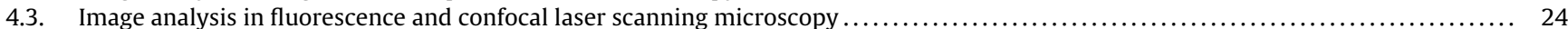

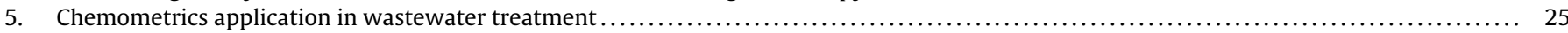

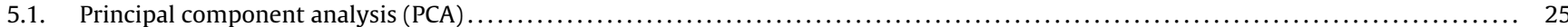

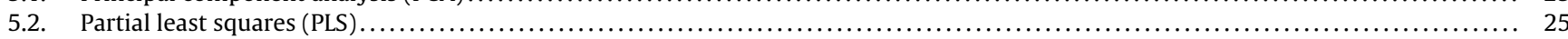

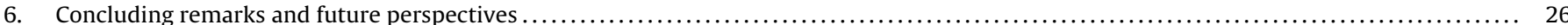

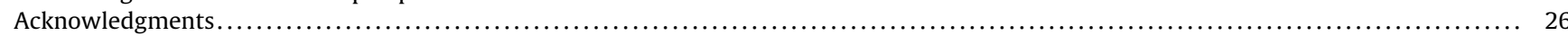

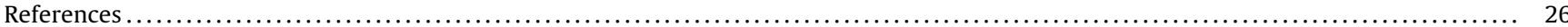
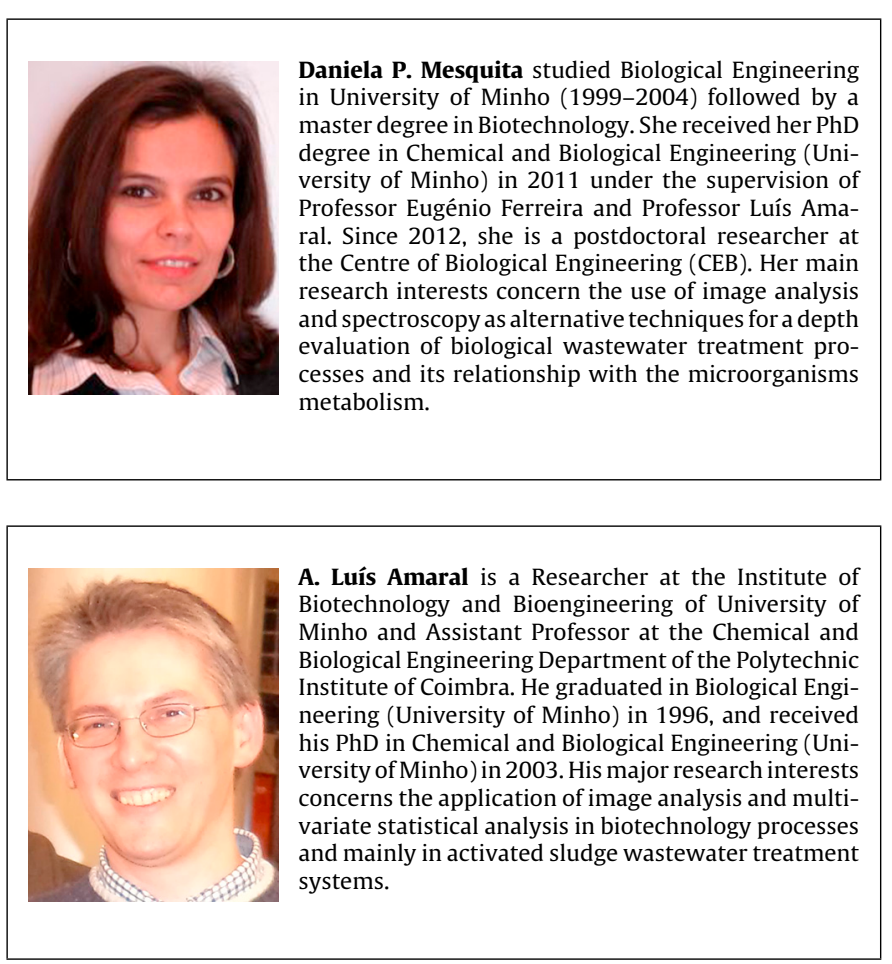

\section{Introduction}

The emergence of wastewater treatment processes to solve water quality issues led to the development of activated sludge (AS) systems, as the main biological process in wastewater treatment plants (WWTP). This system is composed of an aerated tank where the biological conversion of the contaminants takes place and of a clarifier where the AS is subsequently separated from the treated effluent by settling. In the aerated tank, microbial organisms oxidize pollutants, causing the organic matter and nutrients to be removed from the wastewater, given oxygen supply.

The sludge settling ability is considered one of the main problems in AS systems and is commonly measured by the sludge volume index (SVI). Therefore, sludge flocculation, stability, aggregates size, morphology, density, and chemical composition are crucial to the efficient operation of an AS system [1-9].

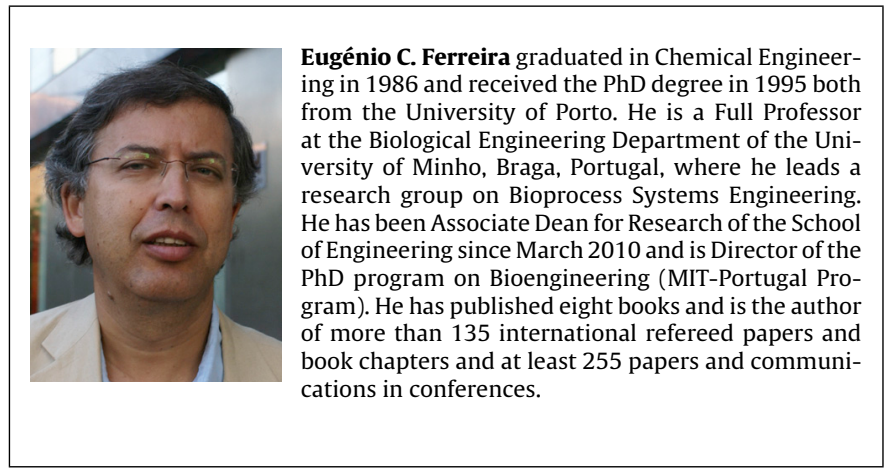

Globally, AS encloses a complex ecosystem composed of different types of microorganisms, such as filamentous and floc-forming bacteria, protozoa and metazoa. Furthermore, due to the complex nature of microbial communities, imbalances between the different types of bacteria may take place and disturb the plant with profound economical and environmental consequences. For this reason, microbial community assessment by microscopy inspection [10-13] is a useful way for a fast malfunction diagnosis. It should be noticed though that microscopy techniques are furthermore useful tools for ecology, hydrodynamics studies, diffusion and sorption of pollutants, which are beyond the scope of this article.

In AS systems, microorganisms commonly appear as microbial aggregates. However, the proliferation of filamentous bacteria in WWTP, compromising the plant efficiency, has resulted in a meticulous survey of these microorganisms. In fact, plant surveys carried out in different countries have shown a large diversity regarding filamentous bacteria with respect to diverse plant malfunctions [14]. Since identifying filamentous bacteria is not an easy task, traditional identification based on its morphology and physiology is still employed using bright-field and phase-contrast microscopy.

Nevertheless, in filamentous bacteria recognition, due to the similarity between some microorganisms many uncertainties have arisen, and therefore a number of different staining techniques were developed. Consequently, for microorganism identification, classical staining methods [13] are referred as the most significant techniques, and more recently, novel nucleic acid binding stains were found to detect microorganism status (such as Gram and viability) based on cell wall composition and integrity [15-19]. Furthermore, and apart from the ability to differentiate between viable/damaged and Gram-positive/Gram-negative bacteria, the 
use of dyes may be applied to identify different intracellular storage compounds. It is stated that information about these intracellular storage polymers and the diversity of microbial population could be invaluable to follow the microorganisms' metabolism [20]. Thus in-depth knowledge of the sludge properties can be accomplished. Overcoming some limitations of bright-field and phase-contrast microscopy, fluorescent in situ hybridization (FISH) (through fluorescence microscopy) has been used in the past few years to determine the contents of specific microorganisms in environmental samples, mainly floc-forming and filamentous bacteria [21-31].

Nowadays, technological evolution and advances in digital imaging allow for a fast and efficient microorganisms classification and quantification. With the increase of computers performance and affordability, quantitative image analysis (QIA) has become a routine analysis in several studies for AS characterization mostly in the research field, although not yet regularly implemented in real WWTP practices. Thus, image analysis is, at present, a wellestablished procedure when combined with optical microscopy, not only for aggregates and filaments monitoring, but also for improving the biological process efficiency through the combination with operational parameters data [6,32-46]. It should be noticed though that some difficulties may be encountered in QIA procedures related to the suitability of the employed microscopy technique regarding the intended sludge characterization. Such may be the case of the bright-field microscopy used to determine filamentous bacteria contents, hampered when there is an overgrowth of filamentous bacteria, or the use of staining techniques in dense aggregates, among others.

The large amount of data that can be gathered in wastewater treatment regarding plant performance, operational, analytical, and physical data, and biomass characterization provided by QIA, requests the use of mathematical and statistical methods for data mining. This could be a challenging opportunity for the quantitative description of experimental results and effects, extracting fundamental information in wastewater treatment using chemometric techniques $[47,48]$. Principal component analysis (PCA) is a useful technique to find patterns in data of high dimension, highlighting their similarities and differences [46]. Other main advantage of PCA is that once found these patterns in the dataset, data compression is possible by reducing the number of dimensions, without significant loss of information [49]. Another statistical technique widely employed, Partial Least Squares (PLS), is particularly useful to predict a set of parameters from a large set of independent variables $[6,41,47]$.

The aim of this review is to discuss the recent advances in AS characterization based on the application of microscopic, QIA and chemometric techniques, related to the contents, aggregation and status of the microorganisms involved. An in-depth analysis is performed to summarize the many new findings that have been achieved, and future developments for these biological processes are further discussed.

\section{Activated sludge monitoring through microscopic examination}

The basis of AS systems is the growth of floc-forming bacteria upon a filamentous bacteria backbone which settle under gravity in the final clarifier, leaving a clarified supernatant and a thickened return sludge. Thus, the success of a given AS system depends on a correct balance among floc-forming and filamentous bacteria $[50,51]$. A variety of other factors is also known to affect settling rates due to flocculation and deflocculation processes [52].

Shape, structure, and strength of AS flocs are three important characteristics regarding morphological characterization. Shape varies in its regularity, roundness and compactness, among others. If the flocs present highly irregular shapes, or present an open nature, consequently, the sludge settling velocity is reduced. Although, according to Eikelboom [12], the presence of weak flocs could be inferred by the large presence of cells at the floc edge, promoting their degradation, when establishing the strength of a floc other methodologies, such as shear sensitivity [53], are preferable. On the other hand, if compact flocs are present, bacteria are stacked close to one another, leading to higher settling velocities. It should be noticed though that, the air supply in the aerated tank and the presence of protruding filamentous bacteria leads to flocs irregularly shaped, and typical floc characteristics include irregular shape, broad distribution of particle sizes, fragile and easily compressible, highly porous and permeable to fluids, large specific surface areas, inhomogeneous distribution of internal mass, networked structure, and poor dewaterability [54,55]. Other morphological, physical, and chemical factors, including particle surface properties, particle size, extracellular polymeric substances (EPS), and flocculating ability were also referred as affecting the solid-liquid separation processes in AS systems [2,5,56-64].

The most common problems in AS systems were reported by Jenkins et al. [13] comprising pinpoint flocs formation, filamentous bulking, dispersed growth, and viscous (or zoogleal) bulking. Hence, overproduction of EPS by floc-forming bacteria, and filamentous bacteria under or overgrow, can lead to operational problems. These problems arise mostly when the operating conditions are not perfect mainly in terms of organic load, nutrients, and oxygen supply. Although the occurrence of any of the phenomena here identified can negatively affect the clarifier performance, sludge bulking is one of the most significant problems. Bulking can cause severe operational problems, increasing the treatment costs and lowering the final effluent quality. The most critical problems involve poor settling ability, risk of sludge washout with the final effluent and deteriorated dewatering and thickening properties of the sludge [12].

Understanding AS problems requires sludge characterization with respect to the aggregated and filamentous biomass contents, and filamentous microorganisms' identification through microscopic examination. It is known that the microbial aggregates characteristics, including their internal structure, chemical composition and microbial ecology, determine the transport properties and chemical reaction rates, and affect the overall performance of the treatment processes [65]. As microscopes allow the visualization of AS, microscopic examination is quite useful for determining the physical nature of the aggregated biomass, and the type and abundance of filamentous microorganisms [13]. Consequently, the determination of the AS biomass characteristics, related to settling and compaction, allows microscopic techniques to yield information related to the AS behavior in solid-liquid separation processes. As most microscopes are now fitted with a range of options for bright-field, phase-contrast or fluorescence microscopy further insight on these techniques is presented and discussed in the following sections.

\subsection{Light microscopy}

\subsubsection{Bright-field microscopy}

Sezgin et al. [66,67] and Sezgin [68] were the first authors to demonstrate a strong relationship between SVI and filamentous bacteria contents, using a procedure relying on manual counting with an eyepiece micrometer in bright-field microscopy. Furthermore, these authors proceeded to study the influence of organic loading on floc size distribution in AS using the same methodology [59]. However, manual counting techniques are rather time-consuming making them not feasible in wastewater treatment laboratories. Hence, some authors have tested quite simple automated image analysis methods to quantitatively characterize 
the aggregate morphology, and relate properties as floc fractal dimensions to the sludge settling ability $[56,57,60,69]$. Furthermore, recent advances on floc structure analysis associated to microscopic techniques gave access to a deeper knowledge with respect to the aggregates structural information and strength [70] and are further discussed.

\subsubsection{Phase-contrast microscopy}

It has been already seen that bright-field microscopy may provide useful information about the sludge state, especially in conventional AS systems where floc-forming bacteria dominate, increasing the aggregates size and compactness. In spite of the affordability provided by bright-field microscopy, the transparent nature of the majority of microbial cells, including filamentous bacteria, hinders their visualization since they lack contrast. To overcome this problem, the use of phase-contrast microscopy is invaluable [71] for determining specific characteristics in filamentous bacteria identification, such as the presence of branching or sheath [13], hardly visible in bright-field. In fact, phase-contrast microscopy, which differentiates density diverse structures, can be used to visualize AS internal structures without staining [41], and contrast filamentous bacteria. Fig. 1 shows two images obtained using bright-field and phase-contrast microscopy, where the higher contrast of filamentous organisms using phase-contrast acquisition is clearly visible. Considering the advantage and disadvantages of both, in AS characterization, bright-field microscopy proved to be more precise for aggregates' borders determination and assessment of short protruding filaments while, phase-contrast microscopy was found to favor the assessment of long protruding filaments [43], promoting filamentous bulking conditions identification. However, the use of bright-field microscopy presents some limitations in AS characterization, regarding the assessment of specific microbial communities and/or several intracellular storage compounds, unable to be identified.

\subsubsection{Bright-field microscopy staining}

It is known that the physiological characterization of different types of bacteria is able to be performed using bright-field microscopy coupled to staining procedures. Two staining procedures are used routinely in filamentous bacteria identification Gram [72-74] and Neisser [73] staining. The Gram staining method, and the differentiation between positive and/or negative status, depends on the existence of a permeability barrier in bacteria based on the chemical and physical properties of the cell wall. The reaction to Gram staining could be negative, strongly positive or weakly positive. Although a large variety of the filamentous microorganisms present in AS systems are Gram positive, a significant amount of Gram negative bacteria is also commonly observed in AS systems. This characteristic is helpful to determine the filamentous bacteria contributing to poor settlement of AS flocs, by bulking or foaming, in secondary settling tanks as Sphaerotilus natans, Type 1701, Type 021N and Type 1863 are Gram negative and Actinomycetes, Microthrix parvicella, Nostocoida limicola, Type 0914, Type 0041, Nocardia are Gram positive. The Neisser staining is based on the dye retention mechanism in the cell walls or granules of certain bacteria. Blue-violet cells (sometimes purple in appearance) are considered positive and yellow-brown cells negative. Commonly, this staining procedure is an indispensable aid to the identification of certain strains of filamentous bacteria [12]. Furthermore, Neisser staining can also be used to determine polyphosphate inclusions within the microorganisms [75]. Other staining methods are commonly used in bright-field microscopy for the determination of intracellular inclusions such as polyphosphate by Methylene Blue [72] and polyhydroxyalkanoates (PHA) [including poly- $\beta$-hydroxybutyrate (PHB)] by Sudan Black B $[72,73,76]$. Furthermore, and regarding polyphosphate inclusions identification as intracellular storage polymers, promising results have also been already reported in enhanced biological phosphorus removal (EBPR) systems by using Methylene Blue staining [31]. The use of Sudan Black B to analyze PHA granules was already tested and successful results have also been achieved in an EBPR system [77]. Glycogen can be identified using periodic acid-Schiff(PAS) staining. However, this procedure is nowadays routinely used only in histology [78]. Regarding AS samples, the application of bright-field staining procedures for glycogen detection has been questioned and has rarely been used since available direct staining techniques up to now do not give reliable results [75]. Using electron microscopy, glycogen was successfully observed in an EBPR system [79]. Fig. 2 shows images obtained using Gram, Neisser, Methylene Blue, and Sudan Black B staining methods.

Nevertheless, traditional Gram, Neisser, Methylene Blue and Sudan Black B staining techniques may be problematic since they require practice, accuracy and precision in the discoloration step, and may be of limited application in large and dense flocs which do not decolorize correctly. At the same time, bright-field or phasecontrast microscopy may not be able to answer some questions about microbial communities such as species composition, structure and bacterial distribution. Thus, fluorescence microscopy, although more expensive, provides the user with a more powerful technology for these purposes, by the use of fluorescence based staining procedures.

\subsection{Fluorescence microscopy}

\subsubsection{Fluorescent in situ hybridization (FISH)}

Using fluorescent probes is an attractive way to overcome some problems for studying microbial populations. Fluorescent probes are short sequences of DNA (16-20 nucleotides) labeled with fluorescent dyes, that recognize $16 \mathrm{~S}$ rRNA sequences in cells and hybridize with them in situ (DNA-RNA matching). As a consequence, microorganisms can be identified and quantified in almost all ecosystems with hybridization [80]. Therefore, the combination of fluorescence microscopy with FISH probes is considered a powerful tool for in situ identification of microorganisms in AS systems. Studies on the characterization of filamentous organisms were already performed through the use of specific probes: $S$. natans and Haliscomenobacter spp. [21], Eikelboom type 021N group I, II, II [27], Candidatus and Microthrix [24] and Gordona amarae [23]. Moreover, more studies have focused on $M$. parvicella, the dominant and the most studied filamentous bacteria present in WWTPs causing regularly bulking and foaming phenomena in AS treatment plants throughout the world $[51,81,82]$. Also, $N$. limicola is largely studied due to their incidence in foaming and bulking phenomena [83-85]. Recently, FISH analysis was also applied to samples obtained from a full-scale plant and related to floc stability [4]. In the case of EBPR systems, FISH staining potential is being currently studied linking the process performance with the microbial community [31,86,87]. Furthermore, the review of Sanz and Köchling [88] emphasizes the FISH application for AS processes such as: (1) nitrifying populations' discrimination, (2) Anammox bacteria identification and (3) distinction of specific organisms in EBPR systems. However, there are some crucial disadvantages, regarding FISH analysis, related to the need of previous knowledge of the microbial population and dominant microorganisms under study in order to be detected. Apart from the identification of the AS bacterial species, this molecular technique was previously used to quantify different types of bacteria in AS, based on rating systems determining abundance categories by direct microscopy observation and manual count [30]. It was also used to quantify nitrifying bacteria by estimating the volumes of the aggregates, where positively labeled aggregates were manually counted and the average diameter of every aggregate was determined with the aid of an ocular with an implemented grid 

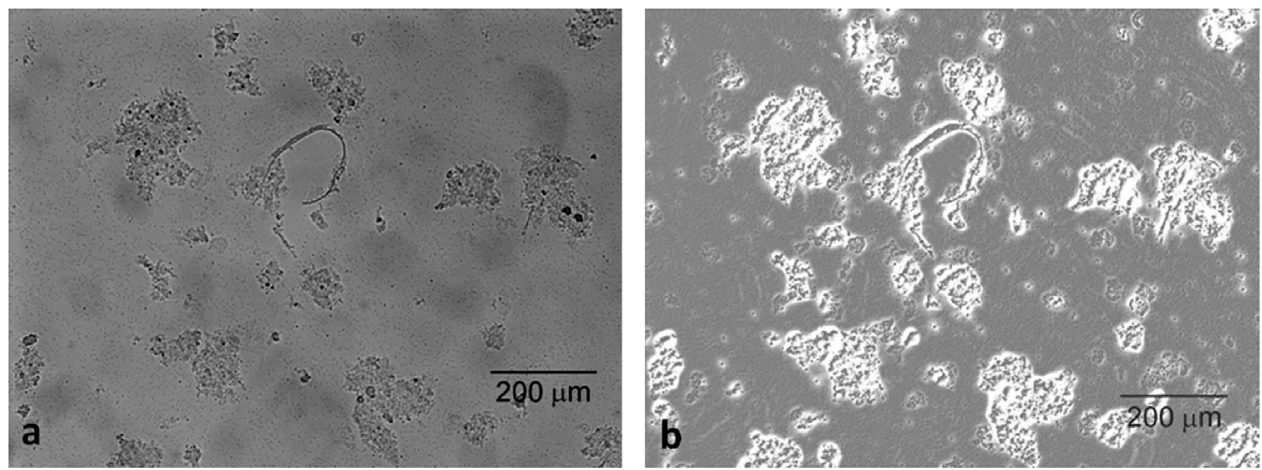

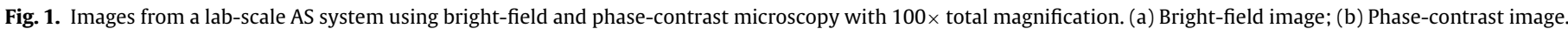

[89]. However, the quantification may be complex and subjective using manual counting and non-uniform fluorescence intensity values can cause problems to automatic quantification procedures. In fact, several causes and solutions for missing or low FISH signals are described by Wagner et al. [90]. Furthermore, FISH application for image acquisition is also highly dependent on the sample density.

\subsubsection{Fluorescent staining}

Beyond FISH, rapid fluorescent staining methods were developed to estimate bacteria viability and Gram status. Hexidium iodide (HI) is a novel fluorescent nucleic acid binding dye that allows the assessment of Gram status by differential absorption through bacterial cell walls, selectively staining Gram-positive organisms without fixatives [89]. The use of such fluorescent dye may provide a robust, objective, and rapid alternative to traditional Gram staining in wastewater systems $[16,45]$. The Live/Dead ${ }^{\circledR}$ BacLight $^{\mathrm{TM}}$ Bacterial Viability kit [17] is a widely used method to measure viability and differentiate between living and dead cells by detecting membrane integrity, even in a mixed population containing a broad range of bacterial types [17]. This kit is comprised by two nucleic acid probes, green-fluorescent SYTO ${ }^{\circledR} 9^{\mathrm{TM}}$ and redfluorescent Propidium Iodide (PI). These stains differ both in their spectral characteristics and in their ability to penetrate healthy bacterial cells. This kit was successfully used in drinking water and AS samples [29,45,92,93] (Fig. 3). Another fluorescence based kit has been already successfully used combining Gram and viability staining in AS samples [19]. The ViaGram ${ }^{\mathrm{TM}}$ Red+ Bacterial Gram Stain and Viability Kit [94] provides a fluorescent staining that differentiates Gram-positive and Gram-negative bacterial species and, at the same time, discriminates live from dead cells on the basis of membrane integrity. This kit contains two nucleic acid stains: 4-,6-diamidino-2-phenylindole (DAPI) and SYTOX ${ }^{\circledR}$ Green for viability determination. Bacteria with intact cell membranes stain fluorescent blue with DAPI, whereas bacteria with damaged membranes stain fluorescent green with SYTOX ${ }^{\circledR}$ [19]. The Texas RedX $_{\text {CWGA }}$ selectively binds to the surface of Gram-positive bacteria
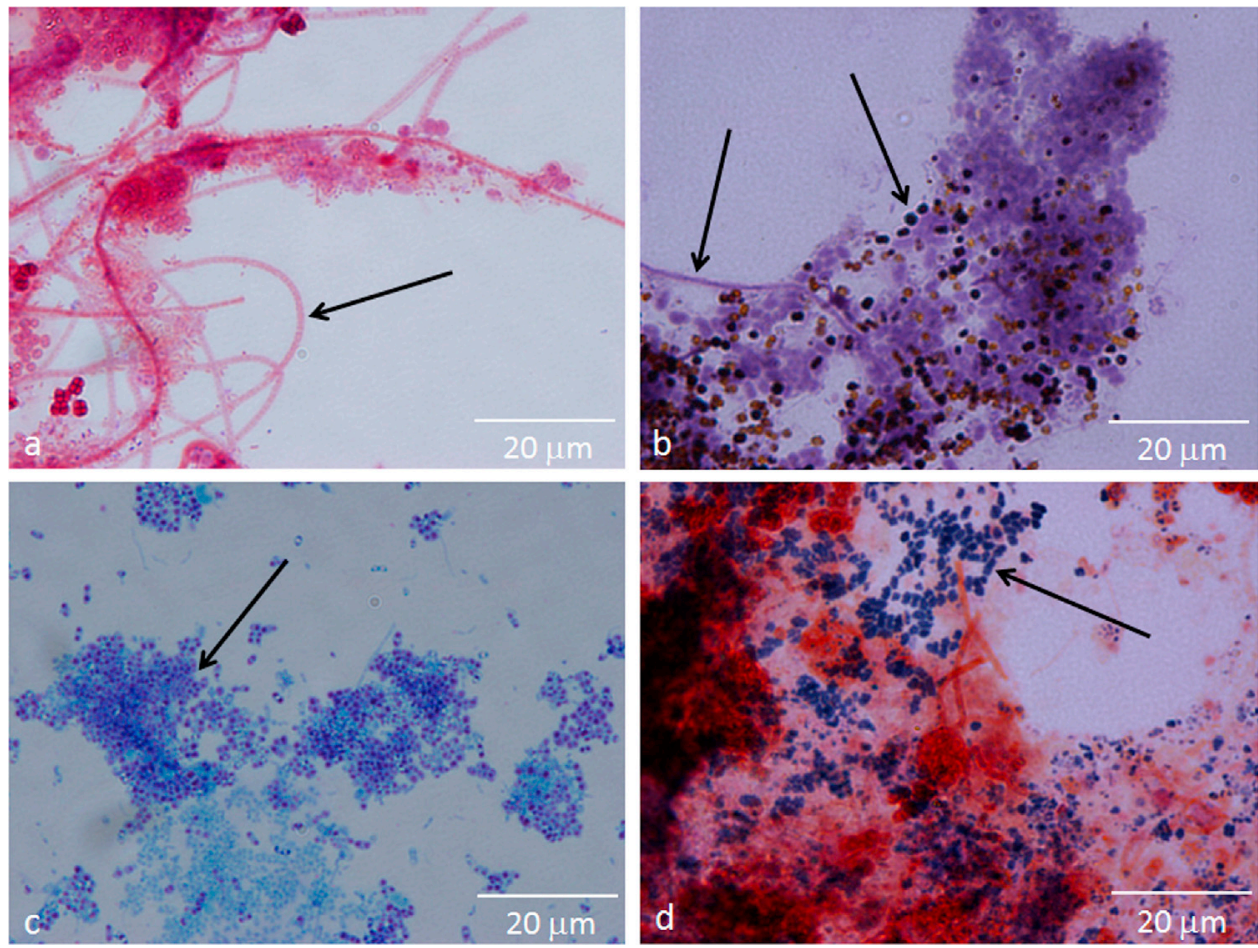

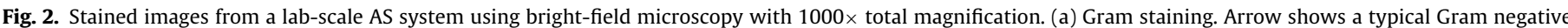

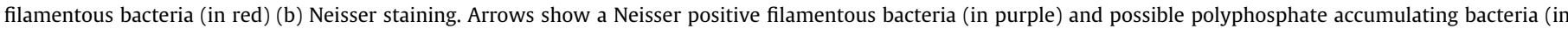

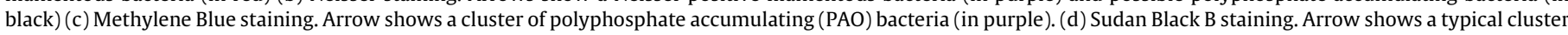
of PHA accumulating bacteria (in dark blue) (for interpretation of the references to color in this figure legend, the reader is referred to the web version of the article). 

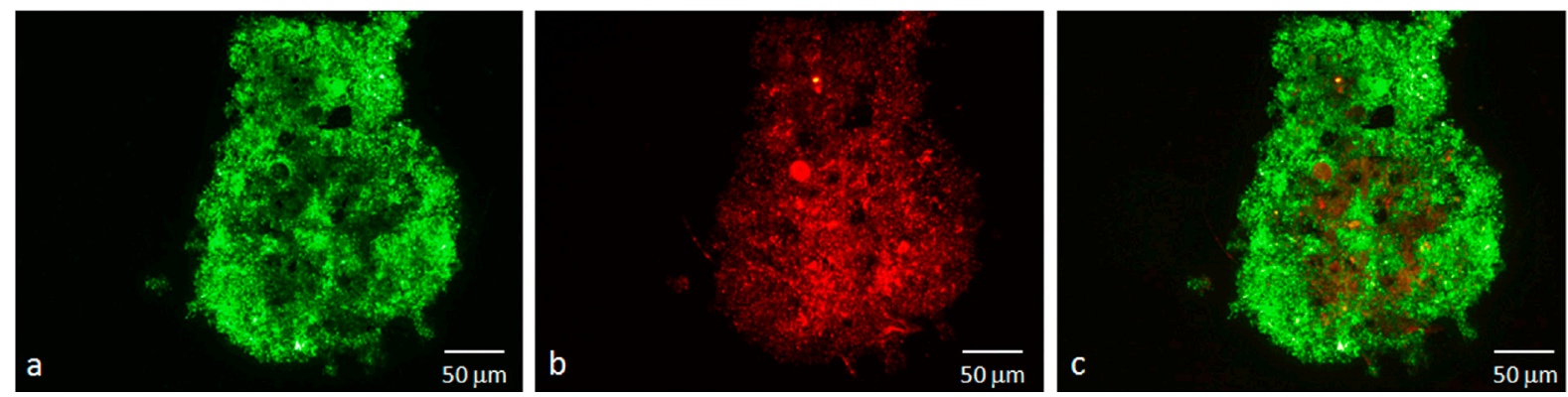

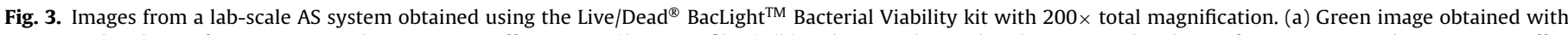

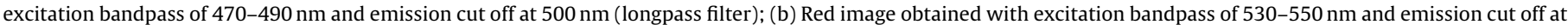
$570 \mathrm{~nm}$ (longpass filter); and (c) Images (a) and (b) merged.

and stains them fluorescent red. With three fluorescent colors, the four possible combinations - live vs dead cells and Gram-positive vs Gram-negative cells - are distinguished. Gram-negative live cells are stained fluorescent blue; Gram-positive live cells fluorescent blue in the interior and red in the surface; Gram-negative dead cells are stained fluorescent green; Gram-positive dead cells fluoresce red on the surface and green in the interior [94]. This last described kit could be the best option when viability and Gram status of AS characterization are the main purposes, since with only one staining procedure the ensemble information is obtained. Moreover three colors staining procedures are not well adapted to fluorescence microscopy due to risk of overlapping fluorescence signals. Regarding the disadvantages pointed out for FISH probes (Section 2.2.1), for these particular fluorescent nucleic acid binding dyes, the same intensity and density problems arise. Thus, sample preparation studies, and specific image acquisition methodologies should be performed for a successful application of image analysis procedures and prevent the loss of the biological process knowledge.

Combined with FISH or otherwise, fluorescent staining samples with DAPI [95], at high concentrations, and Nile blue [96] dyes, can be applied to visualize polyphosphate granules and PHA inclusions, respectively. Furthermore, Shennawy et al. [97] reported the use of Aniline blue to stain glycogen inside cells. A more detailed description about the different staining techniques can be found in Serafim et al. [75]. DAPI is regularly combined with FISH for the detection of nucleic acids and simultaneous identification of specific microorganisms in fluorescence microscopy. In the case of polyphosphate granules identification, DAPI staining depends on a polyphosphate-mediated metachromatic reaction, which causes a shift in the emitted fluorescence from blue to bright yellow-green [98]. It has been already found that at high concentrations, DAPI reacts with both DNA and polyphosphate, with poly-P-DAPI complex fluorescing as bright yellow while the DNA-DAPI complex fluoresces as sky blue $[99,100]$. Therefore, bacteria which accumulate large amounts of polyphosphate will be easily distinguished, with DAPI staining, as they fluoresce yellow $(525 \mathrm{~nm})[101,102]$, for an excitation wavelength of 330-385 nm [103]. However, it has been also stated by Streichan et al. [95] that high concentrations of DAPI $\left(50 \mu \mathrm{g} \mathrm{mL}^{-1}\right)$ stain both polyphosphate granules and lipid inclusions, although with background fluorescence problems. A different DAPI concentration $\left(5 \mu \mathrm{g} \mathrm{mL}^{-1}\right)$ has already been used for polyphosphate granules identification for an excitation wavelength of $360 \mathrm{~nm}$ and emission between 400 and $650 \mathrm{~nm}$ [104]. As reported by Serafim et al. [75], the distinction between the two storage compounds is based on the fluorescent intensity as the lipid fluorescence is weaker and fades in a few seconds while polyphosphate granules appear bright yellow. PHA inclusions fluoresce orange (600-660 nm) [105,106], for an excitation wavelength between 460 and $600 \mathrm{~nm}$, by Nile blue staining, whereas glycogen and polyphosphate do not absorb enough of the dye to be detected $[96,105]$. However, there are other lipid compounds which are commonly stained with this technique [75]. At the same time, it was stated by the same authors that Nile blue appeared to have a bigger affinity for PHA than did Sudan Black B which was considered the standard staining procedure. The application of Aniline blue stain for glycogen identification for an excitation wavelength of $315 \mathrm{~nm}$ [97], can cause glycogen to fluoresce blue $(430-450 \mathrm{~nm})$, however, as reported by Serafim et al. [75] the staining procedures for glycogen detection has not frequently been used due to inconsistent results. Recently, promising results were already obtained by Mesquita et al. [107] for Nile blue and Aniline blue staining techniques identifying, PHA and glycogen inclusions respectively, in AS with filters differing from the above. For Nile blue staining, a long pass filter was used with an excitation bandpass of $530-550 \mathrm{~nm}$ and the stained PHA inclusions fluorescing red $(625-675 \mathrm{~nm})$. Regarding the Aniline blue staining, a long pass filter was used with an excitation bandpass of $365-370 \mathrm{~nm}$ and the stained glycogen inclusions fluorescing green ( $525-575 \mathrm{~nm}$ ). Fig. 4 shows images obtained from a lab-scale AS system with Nile blue and Aniline blue staining procedures. Taking into account the possibility of using image analysis procedures for these intracellular storage compounds, a previous step of staining optimization is required due to non-uniform dye concentrations problems. Automatic image analysis procedures should facilitate the evaluation and interpretation of the biological processes, regarding the presence of microorganisms presenting intracellular storage compounds, with the benefit of being non-invasive, non-subjective, and fast.

\subsubsection{Confocal laser scanning microscopy}

The confocal laser scanning microscopy (CLSM) can be used for studying the microbial community structure. Fig. 5 shows an image acquired in CLSM. It is a technique where the light microscope has been transformed from an instrument able to view samples in two dimensions to one which can explore structures in three dimensions. Problems related to standard fluorescence microscopy are minimized by CLSM, which is the most powerful non-invasive instrument for studying living samples with a 3D structure [108]. Thus, the use of CLSM for FISH visualization can surpass several problems related to the structure and dynamics of microbial communities, mostly to study samples containing relatively dense aggregated biomass like AS. Nowadays, CLSM is increasingly employed in studies with AS especially to visualize and quantify FISH probed populations [25,26,109-112]. Other characteristics, such as the floc internal structure can also be studied using this technology $[4,113,114]$. Recently, CLSM was combined with a fluorescent viability indicator [17] to study antibiotic toxicity in AS [91], sustaining that even low concentrations were toxic to the sludge. Research on the simultaneous Gram and viability staining was also performed using CLSM, suggesting that toxicity changed 

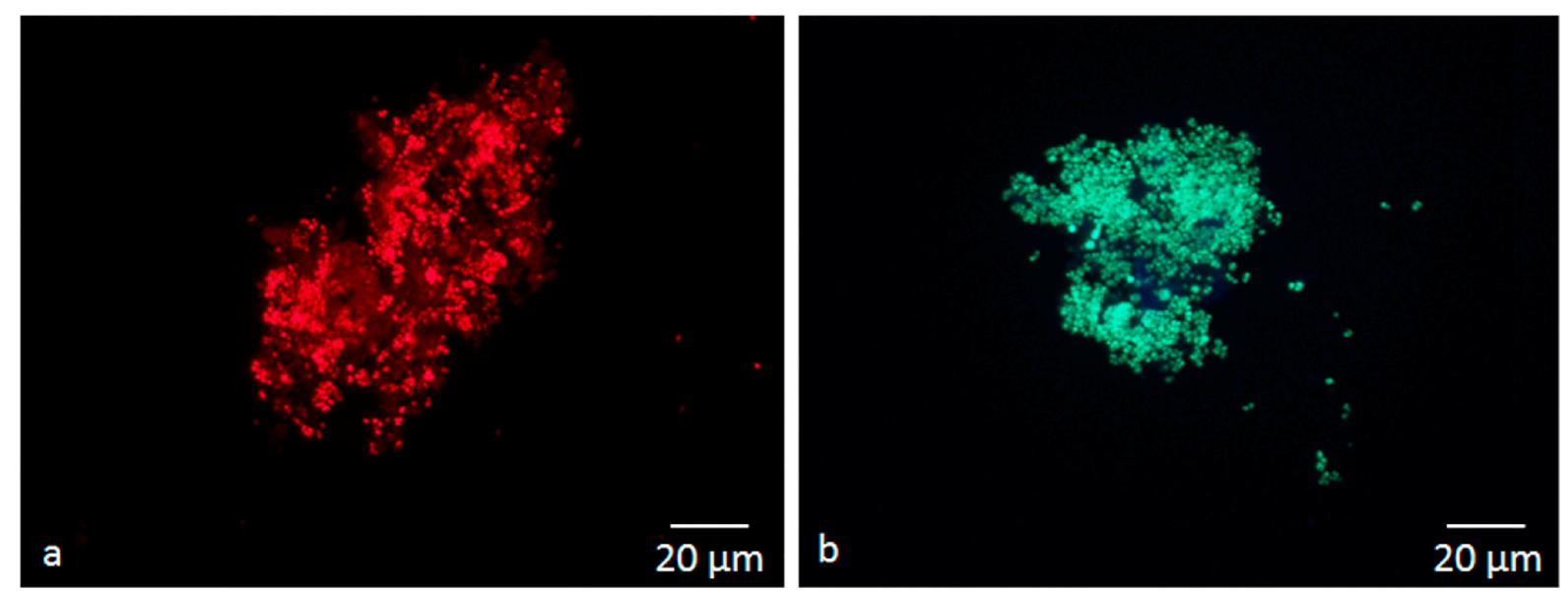

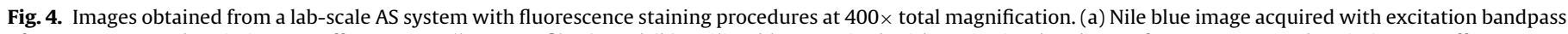

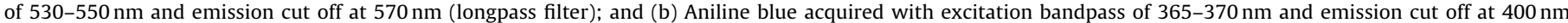
(longpass filter).

AS composition, and also led to bacteria disintegration [19]. The presence of EPS which have a significant influence on the physicochemical properties of microbial aggregates, such as structure, surface charge, flocculation and settling properties has also been studied using CLSM. Thorough analyses of the structural characteristics of AS flocs and spatial distribution of floc components, showing biopolymers, total cells, bacteria, and enzyme distribution, have already been published $[115,116]$. In spite of these advantages provided by CLSM, there are several disadvantages pointed out by Daims and Wagner [108]. Although Daims et al. [109] refers the time constraints for manual counting, requiring high-magnification CLSM sections, which allow single-cell resolution within clusters, this limitation may be surpassed using image analysis programs. In such a case the most important time constraints refer to the time needed to the stacks acquisition. Furthermore the limited accuracy obtained for samples containing densely aggregated cells, stated by these authors, may not occur for the AS sludge samples. However,

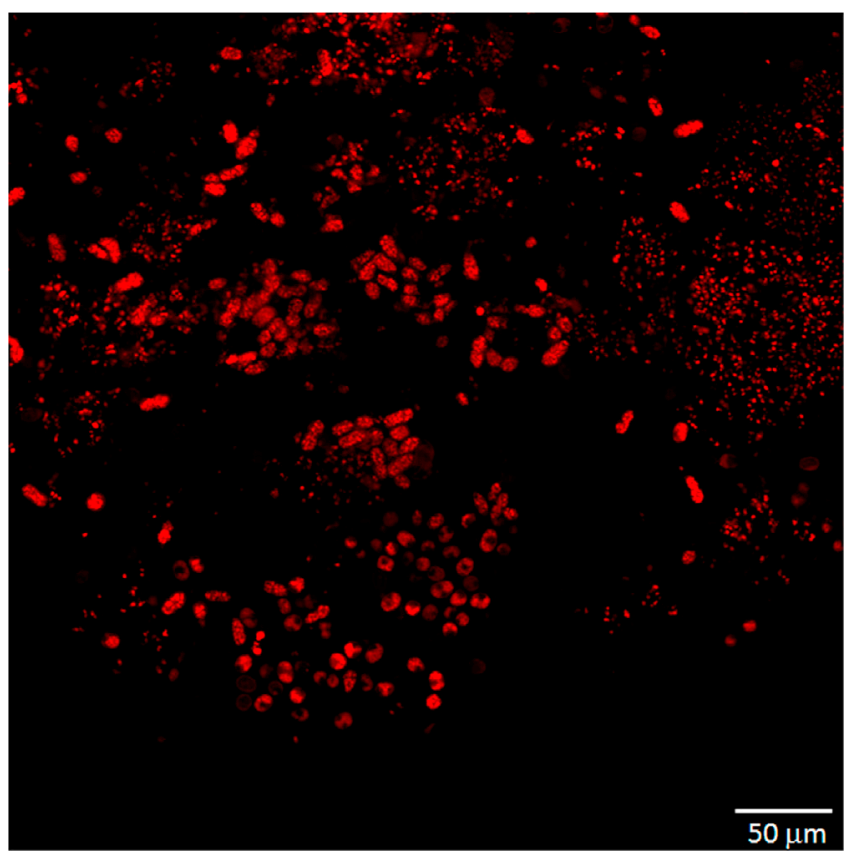

Fig. 5. Image obtained from a lab-scale AS system with fluorescence staining procedure at $100 \times$ total magnification for PHA identification in a Confocal Laser Scanning Microscope. it should always be kept in mind that the cost of the equipment is one of the drawbacks of this methodology. A new technology based on CLS Macroscopy presents advantages over CLSM namely: (1) an extremely wide range of magnification; (2) the ability to record very large data sets, and (3) the ability to image very large specimens [117]. In AS samples, Louvet et al. [93] proved that the level of visible details significantly improved with the use of a CLS Macroscope. The authors found that optical zoom allowed a fast overview of the slides before zooming on a selected AS floc with optimal magnification, and that the three-dimensional structure of flocs could be visualized.

The application of QIA procedures in CLSM images will be further discussed. However, based on the present knowledge, it is known that these procedures must take into account specific algorithms for segmenting three dimensional images, regarding the definition of intensity thresholds to distinguish the objects from the background, depending on the type of sample [118].

\section{Image processing and analysis}

Computers are key equipments for the analysis of large amounts of data, for tasks requiring complex computation, and for the extraction of quantitative information, opposite to the qualitative evaluation of human analysis. Today, the automatic analysis of numerical images captured by digital cameras enables to extract quickly quantitative information [39]. Thus, as a basic concept, image processing and analysis is the extraction of significant information from images, by means of digital image processing techniques.

The diversity of digital image processing applications is continuously growing through all areas of science including: medicine, such as dermoscopy [119], radiography [120,121] and endoscopy [122]; chemistry, such as spectrophotometry [123]; biology [124]; and other fields of applications. Several studies have been already reported coupling digital image analysis with microbial microscopy such as the study of fungal hyphae morphology and physiology [125], yeasts characterization [126-129], Escherichia coli characterization by fluorescence microscopy [130], enumeration and sizing of aquatic bacteria [131], biomass and filamentous species determination [39,41], fungus colonies biochemical and mycelium differentiation [132], and mammalian cells characterization [133].

Regarding the use of this technology, it is essential to take into account the early stages of image capture/acquisition and image processing prior to the image analysis per se. These three steps are 
fundamental to obtain good quality images and extract the most important information from them.

\subsection{Image acquisition}

Image acquisition is, in most cases, performed through the use of digital cameras. The signal produced from the digital camera leads to the formation of a matrix of picture elements (called pixels) directly proportional to the light intensity received by each sensor [134]. The number of bits allocated to the pixels of any given image determines the number of colors in the image. For grayscale images it is common to represent each pixel in 8 bits corresponding to 256 gray levels. Commonly, monochrome images have been acquired for bright-field (without staining), phase-contrast and even fluorescence (with a single fluorescent dye or narrow bandpass filters) microscopy. In the latter case the intensity, at a given emission wavelength, is the prevailing factor for further analysis and thus monochrome cameras can be used, due to their high sensitivity. In optical and fluorescence imaging the largest problems regarding image acquisition are the correct focusing and, for the bright-field and phase-contrast also the non-uniformity of the background illumination. Regarding the fluorescence microscopy, fading, bleaching and background fluorescence problems need also to be dealt with. These issues should be studied and optimized prior to the acquisition of the images, for a well succeeded image processing and analysis procedure. Most real-world images, however, are not monochrome, but colorful. Light microscopes produce color images, and many preparation techniques make use of color, for example, to identify structure or locate chemical activity in novel ways. Staining procedures using bright-field are, therefore, commonly applied, producing color images. Also in fluorescence microscopy color images may be acquired. Such is the case when two or more fluorescent dyes are used, in the same sample preparation, to distinguish objects or structures, and the visualization of the different dyes accomplished using a longpass filter. In this case, both the intensity at a given emission wavelength and the wavelength (color) itself are relevant factors. In color imaging, the use of color scales as a substitute for brightness values allows determining small changes in the color space that can't be identified by the grayscale brightness values alone [134]. In this case images are typically digitized as 24-bit RGB (red, green and blue channels), meaning that 8 bits or 256 (linear) levels of brightness for red, green, and blue are stored [134]. Apart from the problems needed to be resolved above mention for monochrome images, color imaging may present problems of their own. Such is the case when the colors to be recognized are too similar in the RGB spectrum, given the limited number of bits allocated to each color in the digital camera.

\subsection{Image processing}

The purpose of the image processing step resides on obtaining a final image, usually grayscale or binary, holding significant information for a given application. First, images are pre-processed, including background determination and elimination, and image enhancing operations. Subsequently, segmentation is performed to separate the objects from the background by using spatial or frequency domain segmentation methodologies. In order for segmentation to take place, a threshold value or values must be defined to allow the differentiation between the objects and the background. Obtaining a binary image (pixel value of 1 for objects and 0 for background) is a critical step, which should be automated as much as possible to avoid subjectivity (differences of appreciation between operators) [41]. A post-processing of the binary images may be, at times, needed to solve issues like the removal of border objects (cut-off by the borders of the image), removal of debris or the separation of touching objects, among several others. Finally, the binary images can be used directly to perform the image analysis step or serve as mask images to extract the intensity images of the objects or regions of interest [135].

The major challenge of processing color images for quantitative analysis is the difficulty to discriminate, with accuracy, features of significant importance within an image. The problem is that microbial objects of interest in high definition digital color images are commonly represented by pixels with heterogeneous brightness ranges in each RGB channel. To aggravate this, the objects of interest often have shallow gradients of brightness transition at their borders resulting in indistinctive boundaries that contrast gradually with the background [136], and in other cases present bright halos that hamper the boundaries recognition.

\subsection{Image analysis}

This step is performed once the final images from the processing step are obtained. Usually, when working with binary images most common parameters are related to the objects morphology (Euclidian geometry) for instance, equivalent diameter, area, number, perimeter, length, width, eccentricity, roundness, extent, convexity, compactness, and solidity [135]. Sometimes, other parameters related to fractal dimensions are also taken into account when objects have highly irregular geometric shapes [53,137]. Since these parameters reflect the complexity of a given structure such as the case of aggregates from AS systems, an increasing number of studies have been already conducted [41,53,135-139]. However, the nature of these parameters can differ significantly from application to application. In color scales, particularly for fluorescent staining, intensity images, apart from binary, are also commonly determined [140], presenting invaluable information regarding the biomass physiological status and particular components contents determination.

\section{Image analysis application in activated sludge systems}

With a potential application in a number of different areas, unsurprisingly, image analysis has been increasingly used in wastewater treatment monitoring both in fundamental research and as a complementary tool for sludge characterization in aerobic and anaerobic processes, helping clarifying operational behavior and/or malfunctions.

The study of wastewater treatment aerobic processes through the use of image analysis has been performed mainly in AS systems, as they are the most frequent biological processes. Table 1 shows the main achievements in AS characterization using QIA techniques. It was already established that the relationship between SVI and sludge composition (aggregated biomass structure and contents and filamentous biomass contents) is considered of critical importance, making image analysis a powerful tool for biomass inspection and avoiding operator subjectivity.

\subsection{Acquisition, sampling and dilution in activated sludge}

Normally, bright-field or phase-contrast microscopy is used at $100 \times$ total magnification for visualization and image acquisition. However, a study regarding the magnification effects on biomass structure has already been published comparing the acquisition using $100 \times$ and $20 \times$ total magnification [44]. It was concluded that the $100 x$ total magnification allowed for the detection of both small aggregates and filamentous biomass contents while still presenting a good representativeness of the total biomass contents.

One of the critical steps in QIA is the sample preparation. For AS microscopic inspection, a specific volume (normally $50 \mu \mathrm{L}$, $25 \mu \mathrm{L}$, or $10 \mu \mathrm{L}$ ) of AS fresh samples is placed carefully on a glass 
Table 1

AS characterization using QIA techniques.

\begin{tabular}{|c|c|c|c|}
\hline Reference & Plant & Type of microscopy & Main achievements \\
\hline$[6]$ & Full-scale & $\begin{array}{l}\text { Bright-field for aggregates and } \\
\text { Phase-contrast for filaments }\end{array}$ & Method to monitor bulking events \\
\hline [19] & Full-scale & Epifluorescence and CLSM & $\begin{array}{l}\text { Antibiotic could change the activated sludge bacteria composition, according } \\
\text { to their Gram type and bacterial death was followed by bacterial disintegration }\end{array}$ \\
\hline [29] & Full-scale & $\begin{array}{l}\text { Epifluorescence, CLSM, and } \\
\text { TPE-LSM }\end{array}$ & $\begin{array}{l}\text { The selection of the appropriate microscopic technique depends strongly on } \\
\text { the type of microbial aggregates being analyzed }\end{array}$ \\
\hline [32] & Pilot-scale & Bright-field & $\begin{array}{l}\text { Tested the sensitivity of the method for the detection of filamentous bulking } \\
\text { conditions }\end{array}$ \\
\hline [33] & Full-scale & Bright-field & Validation of the method monitoring a plant during 1 year \\
\hline [34] & Pilot-scale & Bright-field & Bulking events easily detected \\
\hline [35] & Pilot-scale and Channel reactor & Bright-field & Filamentous bulking detected using synthetic or municipal wastewater \\
\hline [36] & Lab-scale & Phase-contrast & $\begin{array}{l}\text { Filamentous bulking related to the increase of total filament length and with } \\
\text { change in floc shape }\end{array}$ \\
\hline [37] & Lab-scale & Phase-contrast & Monitor bulking events in a lab-scale system \\
\hline [38] & Lab-scale SBR & Phase-contrast & $\begin{array}{l}\text { Image analysis information as an indication for the amount of suspended } \\
\text { solids in the effluent }\end{array}$ \\
\hline [40] & Lab-scale SBR & Bright-field & Wider range of SVI results related with image analysis properties \\
\hline [42] & Full-scale & Bright-field & Validation of an image analysis procedure in different full-scale AS systems \\
\hline [43] & Full-scale & Bright-field and Phase-contrast & Bright-field image analysis provided the best overall results \\
\hline [44] & Full-scale & Bright-field & $\begin{array}{l}\text { Sample dilutions affects AS content and } 100 \times \text { magnification is the best option } \\
\text { for AS characterization }\end{array}$ \\
\hline [45] & Lab-scale & $\begin{array}{l}\text { Bright-field and } \\
\text { epifluorescence }\end{array}$ & Identification of different types of bulking \\
\hline$[46]$ & Lab-scale & $\begin{array}{l}\text { Bright-field and } \\
\text { epifluorescence }\end{array}$ & Fast, simple and effective methodology for deviating conditions in AS \\
\hline [60] & Pilot-plant & Dark-field & Relate the morphology of the sludge flocs with traditional settling indexes \\
\hline$[62]$ & Lab-scale SBR & Bright-field and TEM & $\begin{array}{l}\text { Sludge flocs at lower solids retention time (SRT) were more irregular and more } \\
\text { variable in size with time than those at higher SRT }\end{array}$ \\
\hline [65] & Full-scale & FISH and CLSM & Several parameters of flocs were obtained by a 3D reconstructed image \\
\hline [69] & Full-scale & Bright-field & $\begin{array}{l}\text { Shape factors were found to be useful as a measure of softness or stiffness of } \\
\text { the flocs }\end{array}$ \\
\hline [74] & Lab-scale & Bright-field & Gram-negative/Gram-positive filamentous bacteria determination \\
\hline [76] & SBR & Bright-field & PHB storage in filaments \\
\hline [93] & Lab-scale SBR & Epifluorescence and CLSM & Antibiotic time-kill activity was quantified \\
\hline [107] & Lab-scale EBPR & Epifluorescence & Novel method for intracellular storage polymers \\
\hline$[109]$ & Full-scale & FISH and CLSM & $\begin{array}{l}\text { Demonstration of a quantified method for enumerating bacteria in samples in } \\
\text { which cells are not homogeneously distributed }\end{array}$ \\
\hline [110] & Full-scale & FISH and CLSM & $\begin{array}{l}\text { Direct determination of the floc volume, heterogeneity factors and the } \\
\text { population structure of AS flocs }\end{array}$ \\
\hline [141] & Lab-scale & Bright-field & Method for quality assessment of AS \\
\hline [142] & Lab-scale SBR & Bright-field & Biomass deflocculation with antibiotics \\
\hline [144] & Shake flasks & Epifluorescence & $\begin{array}{l}\text { Effects on flocs morphology are significantly influenced even at low } \\
\text { concentrations of surfactants }\end{array}$ \\
\hline [145] & Full-scale & Phase-contrast & Flocs and filaments were recognized using shape descriptors \\
\hline [146] & Lab-scale & Phase-contrast & Correlation between SVI and filamentous bacteria and aggregated biomass \\
\hline [147] & Lab-scale & Phase-contrast & Shape descriptors of flocs and filaments correlated with sludge settling ability \\
\hline [148] & Lab-scale & Phase-contrast & $\begin{array}{l}\text { Robust procedure with results for a set of parameter values for a wide variety } \\
\text { of image types }\end{array}$ \\
\hline [149] & Full-scale and Lab-scale SBR & Bright-field & $\begin{array}{l}\text { The number of microbial aggregates and the influence of dilution was } \\
\text { established }\end{array}$ \\
\hline [152] & Pilot-scale & Bright-field & Flocs fractal dimensions related to SVI \\
\hline [153] & Full-scale & Bright-field & Deflocculation of aggregated biomass with salt addition \\
\hline [154] & Lab-scale SBR & Bright-field & Identification of biomass flocculation and deflocculation \\
\hline$[155,156]$ & Lab-scale & Bright-field & $\begin{array}{l}\text { The effect of surfactant on the flocs of activated sludge can be quantitatively } \\
\text { described by the morphological parameters }\end{array}$ \\
\hline [157] & Full-scale & Bright-field & Typical protozoa and metazoa of AS systems were successfully recognized \\
\hline [158] & Full-scale & Phase-contrast & $\begin{array}{l}\text { A thresholding algorithm was developed to automatically separate flocs or } \\
\text { filaments }\end{array}$ \\
\hline [159] & Full-scale & Phase-contrast & Specific parameters were found to accurately classify flocs and filaments \\
\hline [160] & Lab-scale SBR & Bright-field & Floc structure was quantified and related to settling ability \\
\hline [161] & Lab-scale SBR & Bright-field & SVI related with the floc structure \\
\hline [162] & Lab-scale & Phase-contrast & $\begin{array}{l}\text { Competition between filamentous and non-filamentous bacteria related to } \\
\text { dilution rate }\end{array}$ \\
\hline [163] & Lab-scale & Phase-contrast & $\begin{array}{l}\text { Dynamic ARX models were used to predict the settling properties of the sludge } \\
\text { in filamentous bulking }\end{array}$ \\
\hline [164] & Lab-scale & Phase-contrast & AS stability evaluated by total averaged filament length per image \\
\hline [165] & Lab-scale & Phase-contrast & $\begin{array}{l}\text { A great potential for more accurate determination of the bioflocculation } \\
\text { mechanism }\end{array}$ \\
\hline [166] & Lab-scale MBR & Phase-contrast & Monitoring of bioflocculation can prevent irreversible fouling problems \\
\hline$[167]$ & Full-scale MBR & Phase-contrast & $\begin{array}{l}\text { Filterability can be predicted by analyzing the bioflocculation state of activated } \\
\text { sludge }\end{array}$ \\
\hline [168] & Pilot-scale MBR & Bright-field & $\begin{array}{l}\text { Higher SRT contributes to better activated sludge bioflocculation and, as a } \\
\text { consequence, to lower fouling rates }\end{array}$ \\
\hline [169] & Lab-scale & Bright-field and CLSM & $\begin{array}{l}\text { Hospital effluents affect the floc structure, the production of EPS matrix, and } \\
\text { the bacteria population balance }\end{array}$ \\
\hline
\end{tabular}


slide. Sample deposition can be performed by means of a calibrated micropipette with a sectioned tip, allowing the largest aggregates to pass through. One of the most used methodologies consists in covering the slide with a cover slip $(20 \mathrm{~mm} \times 20 \mathrm{~mm}$ or $24 \mathrm{~mm} \times 24 \mathrm{~mm}$ ). The use of such methodology must take care on achieving a sample depth, between slide and cover slip, high enough to avoid disrupting the sludge structure. Images are then usually acquired in the upper, middle and bottom of the slide. This methodology has proved to be adequate for AS characterization [6,33-35,42-46,141]. Other methodologies, similar to the previously described $[89,142]$ use a smear of AS sample (usually $100 \mu \mathrm{L}$ ), spread on a glass slide with a wide-bore pipette, and air dry the sample. This technique is also similar to the traditional Gram staining procedure, however, AS samples are commonly visualized in bright-field only at $100 \times$ total magnification instead of $1000 \times$ total magnification used in Gram staining. It is believed that the most important task in this step is to ensure AS sample integrity and the use of a constant methodology for having representative information about the sludge state.

When AS systems are the main processes in WWTP they may operate with high biomass concentrations requiring a dilution step prior to microscopy analysis. However, this procedure can produce morphological changes in aggregates and free filamentous bacteria previously attached to the flocs, leading to erroneous information [143]. As a matter of fact, the modification of the osmotic pressure when a dilution is performed can trigger biomass to deflocculate, causing subsequent release of floc-forming and filamentous bacteria to the mixed liquor, which can change the aggregate size and morphology [44]. Both the studies of Mesquita et al. and da Motta et al. $[44,143]$ revealed that due to the different influence of dilutions on several key biomass structure parameters, the use of a single correction factor for the overall results seems unfeasible. Therefore, a special attention should be given when high biomass concentration AS are characterized by means of image analysis and the correct operating dilution requires careful consideration. Therefore, dilution is preferably performed to standardize the sample to a fixed mixed liquor suspended solids (MLSS) concentration (e.g., $1 \mathrm{~g} \mathrm{~L}^{-1}$ ) and, if possible, with supernatant to avoid disturbing the floc structure by osmotic or ion exchange effects inducing deflocculation.

The use of an image analysis procedure requires the acquisition of a sufficient number of images per sample. However, this definition varies among the published studies in AS samples leading to quite different number of acquired images between studies. Grijspeerdt and Verstraete [59] found that at least 150 objects, corresponding to about 10 images, should be analyzed in order to obtain statistically relevant results. Liwarska-Bizukojc and Bizukojc [144] further extended that number, establishing a number of 40 images as sufficient to obtain statistically relevant results. The minimum number of acquired images was also discussed by Jenné et al. [145] finding a strong fluctuation of aggregated and filamentous bacteria contents until 50 images were acquired, corresponding to around 900 objects (including aggregates and filaments). Such was also the number of acquired images in a number of other studies [36-38,93,146-148]. Even more images per sample were acquired by da Motta et al. [33] in their studies, considering a number of 70 images adequate to provide reliable results. Finally, around 150 images have been commonly acquired by Mesquita et al. [42-46] and Amaral et al. [141], corresponding to around 3000 objects (including aggregates and filaments) to guarantee representative information in sludge composition. In another approach, Perez et al. [149] found that a total of 300 objects should be included to obtain statistically significant results in AS morphological characterization, corresponding to a different number of images depending on the type of sludge under investigation. The variability in the number of acquired images and objects, by the previous authors, in order to obtain statistically relevant results, indicates that the prior knowledge of the sludge concentration is quite valuable for the image analysis acquisition steps.

\subsection{Image analysis in bright-field and phase-contrast microscopy}

One of the earlier uses of image processing and analysis in AS monitoring was set on the aggregated biomass characterization. In fact, using image analysis techniques, Grijspeerdt and Verstraete [59] found a good correlation between the form factor morphological parameter and the diluted SVI, pointing out the possibility to estimate AS concentration (apart from highly concentrated sludge). Furthermore, Govoreanu et al. [150] studied the most important parameters regarding the aggregated biomass characterization, aggregates size and shape. It is also known that aggregates generated in AS processes have some fractal features, and several morphological properties could be characterized by fractal dimensions. Hence, the concept of fractal dimension was found applicable in the characterization of the flocs geometry, in the process of aggregation $[53,137,151]$. Fractal dimension parameters were then studied to find a threshold value and to distinguish between the "weak" and "firm" flocs by Arelli et al. [152], and a correlation between the flocs fractal dimensions and SVI was established. With a different scope, Mesquita et al. [153,154] studied the aggregated biomass Euclidean morphology in a SBR treating saline wastewaters (synthetic and fishery). Deflocculation of aggregated biomass with salt addition due to pinpoint floc formation, dispersed bacteria growth and protozoa absence was established. Comparing synthetic and fishery wastewaters treatment, sludge flocculation and deflocculation, respectively, were identified, indicating that biomass changes obtained with synthetic wastewater cannot be extrapolated to fishery wastewater. The removal of surfactants was also studied based on image analysis procedures showing its influence on the morphology and activity of aggregated biomass $[155,156]$.

Since AS encloses a complex ecosystem composed of different types of microorganisms including protozoa and metazoa, a procedure for the semi-automatic identification of the main protozoa and metazoa species present in full-scale AS systems was recently developed [157]. This methodology has proved to be adequate in terms of the main protozoa and metazoa recognition, as well as for the operating conditions assessment.

Apart from the aggregated biomass characterization and protozoa and metazoa recognition, image analysis has been increasingly used for simultaneous characterization of AS aggregated biomass and filamentous bacteria in full-scale WWTPs and lab-scale AS systems. A good example are the works of Cenens et al. [158,159], Banadda et al. [146], Arelli et al. [152], Jenné et al. [36-38,145,147,148], da Motta et al. [32-35], Casellas et al. [160], Dagot et al. [161] and Contreras et al. [162]. This later proposed an image analysis procedure to classify objects as either filamentous or non-filamentous organisms based on different shape parameters. Both Banadda et al. [146] and Arelli et al. [152] established correlations between SVI, filamentous bacteria contents and aggregated biomass morphology. Following the works of Cenens et al. $[158,159]$, which proposed an automatic thresholding algorithm for the classification of the aggregated and filamentous biomass, Jenné et al. [145], studied the most important parameters to accurately classify the AS biomass structure. Later, Jenné et al. [36,37,147], in lab-scale experiments, confirmed the relationship between filamentous bacteria abundance and SVI values. Furthermore, and due to the recognition of significant changes in floc shape due to bulking events, Jenné et al. [38] characterized the debris fraction in the sludge, i.e. non-settleable material like very small flocs, short filaments, and small organic and inorganic waste material. This work further demonstrated the usefulness of image analysis 
information to assess the amount of suspended solids in the effluent. Recently, a study was performed in AS systems showing the great potential of image analysis procedure to relate to settling properties as the morphological parameters of AS respond rather fast to changing process conditions, especially during filamentous bulking [163]. Image analysis parameters have been also found of great potential to study the stability of the sludge prior to an impact of different operational conditions in a lab-scale reactor after the period of acclimatization [164], and to determine the bioflocculation mechanism of aggregated biomass combined with EPS analysis [165]. The growing interest in membrane bioreactors (MBRs) as valuable alternative for conventional AS systems, conducted to relevant research in the bioflocculation of the sludge using automated image analysis. Van den Broeck et al. [166-168] found that monitoring bioflocculation in MBRs can prevent fouling, estimate the sludge filterability, and the large contribution of the solids retention time to achieve lower fouling rates. Furthermore, full-scale AS systems have been increasingly monitored in the last few years by Amaral and Ferreira [6] and Mesquita et al. [40,42]. These authors found that automated image analysis allowed for the detection of a number of different bulking events, and established strong relationships between the sludge settling properties and image analysis parameters.

A large range of procedures is already available to characterize the sludge concerning aggregated biomass and filamentous bacteria. Regarding the applicability of image analysis procedures in full-scale WWTP, a great number of studies have been conducted, revealing the applicability of this technique as an alternative method for AS characterization, even when operating problems, mostly related to the settling ability of the sludge, are present.

Most research described above was performed using monochrome images obtained from bright-field or phase-contrast microscopy. However, the use of color imaging is becoming more attractive because the use of color scales as a substitute for brightness values allows detecting changes in the color space. As a matter of fact, QIA procedures, coupled to classic staining techniques, have already been developed using color images for the quantification of the filamentous bacteria Gram status (Gram staining), and the analysis of PHB inclusions (Sudan Black B staining) in filamentous organisms from AS systems [74,76]. In these cases, staining procedures were carried out on biomass smears fixed on glass microscopic slides and observed by optical microscopy at $250 \times$ total magnification for an in-depth evaluation of the sludge. However, as stated before (Section 2.1.3) these staining techniques may be of limited application in large and dense structures.

\subsection{Image analysis in fluorescence and confocal laser scanning microscopy}

As previously mentioned, a diverse range of fluorescent stains is available for the scientific community to visualize different types of intracellular storage compounds in a complex community of AS. In accordance, image analysis procedures have been already developed and applied to complex samples from an EBPR system to quantify intracellular storage polymers such as glycogen by Aniline blue staining, and PHA by Nile blue staining, using a standard fluorescence microscope [107].

Currently, fluorescent stains are increasingly used to quantify the relative abundance of specific microorganisms. FISH staining techniques are, nowadays, one of the most widely used processes to identify the bacterial community in an AS system, as the studies of Daims et al. [109] pointed out. AS flocs were further characterized using FISH by CLSM and image analysis by Schmid et al. [110] and related to the sludge settling ability. The developed image analysis procedure was based on the differentiation between the background and the floc structure using a threshold taking into account the variation of intensity in different stacks acquired at different depths for each sample. They concluded that the combination between CLSM and image analysis could be a powerful method for direct determination of the floc volume, heterogeneity factors and the population structure of AS flocs. Furthermore, Daims et al. [109] developed a protocol to determine the concentration of bacteria in environmental samples by a combination of FISH, CLSM, and digital image analysis, demonstrating the utility of this type of quantification for enumerating bacteria in samples in which cells are not homogeneously distributed. In their studies the most relevant contribution relied on the image segmentation threshold determination by using a rapid automated threshold selection or iterative algorithms [108,118].

Beyond FISH, several works have been performed to establish the physiological state of the AS biomass using fluorescent dyes such as: Live/Dead ${ }^{\circledR}$ BacLight ${ }^{\mathrm{TM}}$ bacterial viability kit $[17,45,93]$, Live Baclight ${ }^{\mathrm{TM}}$ bacterial Gram stain $[45,46]$, and ViaGram ${ }^{\mathrm{TM}}$ Red+ Bacterial Gram Stain and Viability Kit [19]. Mesquita et al. [45] studied the biomass composition from aggregated and filamentous bacteria, on Gram-positive/Gram-negative and viable/damaged bacteria. This work resulted in the identification and characterization of a number of different bulking problems in a conventional AS system through the direct correlation of the collected data with SVI and MLSS. Furthermore, the usefulness of a fluorescent viability indicator combined with CLSM was established by Louvet et al. [93] during a toxicity study in AS samples. The inhibition ability of an antibiotic in AS samples using a combined kit for viability and Gram differentiation by CLSM, showing the AS composition changes was also previously reported [19]. More recently, QIA was applied with CLSM microscopy to study the effect of hospital effluents on AS. Stalder et al. [169] found that the floc structure, the production of EPS matrix, and the bacteria population balance were affected by those effluents. An in-depth knowledge to link the phylogenetic identity to the activity of the bacteria under investigation has been also studied in CLSM through the combination of microautoradiography (MAR) and FISH. This technique may be quite helpful on establishing the uptake activity of nutrients, and other compounds, to given microorganism species. Nielsen et al. [170,171] concluded that an actual quantitative method could be very valuable in the direct study of ecophysiology of bacteria in complex environments, and in the assignment to phylogenetic groups combining MAR-FISH and CLSM.

Apart from light, fluorescence and CLSM microscopy, a number of other microscopy techniques has already been essayed for AS characterization. As an example, the study of Lopez et al. [29] using fluorescence microscopy, CLSM, and two photon excitation laser scanning microscopy (TPE-LSM) revealed that for flocs with high cell densities, the use of TPE-LSM is preferred, providing a clearer image of the internal structure of the aggregate. Moreover under the appropriate power multi-photon excitation with near infrared light is far less damaging to many living samples. However, for typical AS flocs fluorescence and CLSM proved to be adequate. Regarding full-scale WWTP applications, the more affordable fluorescence microscopy could be promising for a routine monitoring of microbial structures characterization in AS.

In color images, due to the large spectrum of applications further efforts in image analysis procedures is still needed. This is due to the large range of applications: (1) bright-field imaging to identify different types of microbial organisms and inclusions of specific compounds, (2) FISH for a specific microbial population, or (3) fluorescent imaging to study the physiological state of the sludge and intracellular storage polymers. The combination of several of these color staining procedures with QIA could help clarifying the nature of an operational problems in full-scale WWTP. 


\section{Chemometrics application in wastewater treatment}

The term "chemometrics" is usually associated to mathematical, statistical, and chemical methods. Recent advances in computer and instrumentation techniques lead to the collection of large amounts of data from different processes that are best treated by the integration of these methods. Chemometrics tools can, therefore, be used for a wide variety of tasks, including the evaluation and interpretation of data, the optimization and development of predictive models of processes and experiments, and finally the extraction of a maximum of information from the experimental data $[172,173]$. Nowadays, multivariate statistical analysis has become a very important tool to extract useful information from datasets in order to improve process performance and product quality [174].

In environmental analysis the processes and reactions are often non-stationary, irreversible, and take place in systems which are difficult to define, and impossible to describe using deterministic models [173]. The increasing use of chemometrics in environmental studies over the last two decades corresponds to the intensive research devoted to test, and proves the power of data processing techniques in this field. Three main areas of interest can be distinguished in chemometric environmental studies: quantitative chemical analysis, monitoring for environmental quality assessment and modeling and prediction of toxicological effects [175]. In WWTPs, and due to regulations for effluent quality, the detection of disturbances is very important for the optimization of the process performance. Nowadays, the number of assessed variables in WWTPs increased due to computerized measurement devices, hindering dataset interpretation. Therefore, a more systematic way to handle and analyze data is needed to effectively extract relevant information for monitoring and supervision [176].

Multivariate statistical analysis has been already used to estimate influent chemical oxygen demand (COD) loads to a WWTP [177], through artificial neural networks (ANN), allowing the differentiation between situations of low, normal and high influent loads, mainly based on oxygen uptake rate measurements in tanks. Recently, the use of multivariate statistical analysis was found to be important for WWTPs diagnosis in protozoa and metazoan identification. In fact, the recognition of these organisms requires skilled operators and the identification task is labor and time consuming. For that purpose, Amaral et al. [178-180] and Ginoris et al. $[181,182]$ used image analysis associated to multivariate statistical analysis, such as ANN, discriminant analysis (DA), and decision trees (DT). In fact, ANNs are considered to be very effective to capture non-linear relationships between variables in complex systems, and can be applied in situations where insufficient process knowledge is available to construct a model of the system [183].

Some of the most widely used multivariate statistical analyses in WWTPs operation, comprise principal component analysis (PCA) and partial least squares (PLS), given their ability to extract invaluable information regarding the state of the system from large datasets. The work presented in this review addresses multidimensional data treatment using, primarily, these multivariate statistical methods.

\subsection{Principal component analysis (PCA)}

PCA is among the most popular methods for extracting information from data, and has been applied in a wide range of fields. PCA is a multivariate statistical data analysis technique using projection into latent variables (LVs) to reduce high-dimensional and strongly correlated data to a much smaller dataset that can then be easily interpreted. PCA has also been reported as a useful technique for determining correlations between large numbers of variables in a dataset. PCA acts by changing the high-dimensional datasets into low-dimensional datasets via the linear combination of variables constituting the original datasets. This approach is important for problems with a large number of input variables and features in chemical and biological processes. If some of the measured variables are linearly related or contaminated by errors, the first few components capture the relationship between the variables, and the remaining components are composed only of error. Thus, eliminating the less important components reduces the contribution of errors in the measured data and represents it in a compact manner [184].

Many researchers have already used PCA for wastewater treatment disturbances diagnosis [48,185-190] and for toxicity evaluation [191]. Paper mill wastewaters were also evaluated through physical-chemical parameters combined with EPS production by cells using PCA analysis [49]. These authors found that in WWTP with high EPS production, the statistical analysis allowed to show the contribution of the nitrification process and the presence of $\mathrm{PO}_{4}{ }^{3-}$ nutrients, for stable sludge and good settling properties. Furthermore, high-dimensional data from QIA strengthen the need of multivariate statistical techniques for these purposes. Such was the case of Jenné et al. [147] that applied PCA to find the parameters from image analysis datasets more related to the SVI. PCA techniques have also been successfully applied for monitoring a wide range of wastewater treatment systems using spectroscopy [192-194]. More recently the study of Mesquita et al. [46] focused on PCA analysis for the detection of AS systems abnormalities using data collected from aggregated and filamentous biomass, biomass composition on Gram-positive/Gram-negative bacteria and viable/damaged bacteria, and operational parameters. Results allowed the identification of several disturbances, namely filamentous bulking, pinpoint flocs formation, and viscous bulking as well as normal conditions by grouping the collected samples in corresponding clusters.

\subsection{Partial least squares (PLS)}

PLS is a linear multivariate statistical method particularly useful to predict a set of dependent (response) variables ( $\mathbf{Y}$ ) from a large set of independent (control) variables $(\mathbf{X})$. In PLS regression, the model determines components (latent vectors) from $\mathbf{X}$ that are also relevant for $\mathbf{Y}$, performing a simultaneous decomposition of $\mathbf{X}$ and $\mathbf{Y}$. The regression method attempts to maximize the covariance between matrices $\mathbf{X}$ and $\mathbf{Y}$. An optimal number of LVs can be estimated using cross-validation (CV) or separate test sets [195]. However, since this is a linear method, a suitable data input selection is needed, otherwise non-linear transformations of the data should be included to accommodate the non-linearity of the pursued model. Furthermore, data normalization, prior to the development of the PLS model, is necessary in order to avoid biasing the weights determination of the input variables. It should also be stressed that the PLS model is limited to the data range used to build the model, and careful must be taken in extrapolating the model beyond that range.

The study of Ferrer et al. [196] revealed that with a PLS approach it is possible to build predictive models for monitoring the performance of WWTPs, help in the diagnosis of a complex batch polymerization process, develop an automatic classifier based on image data, and assist in the empirical model building of a continuous polymerization process. A number of other attempts have been made to implement PLS modeling methodologies on WWTPs. Several applications are focused on predictions of quality parameters of the WWTP influent or effluent, and a considerable amount of the reported results are based on daily average values of the on-line measured variables combined with off-line measured variables [174,197]. PLS was found to predict deterioration of the sludge settling ability properties [197] and isolate disturbances from the 
normal operating conditions [194]. A PLS approach was used to predict the SVI in WWTPs during filamentous bulking events using solely image analysis information [6]. Furthermore, PLS models were recently used to estimate several operational parameters using UV-vis and near-infrared spectroscopy on a lab-scale AS system and in full scale WWTPs [194,198,199]. More recently, studies using PLS analysis were performed using QIA provided by different fluorescent staining techniques for intracellular storage polymers quantification [107], as a promising technique toward an alternative method to analytical off-line measurements.

The combination of different multivariate statistical methods is also commonly used nowadays. Such was the case of the work of Mesquita [140] gathering large amounts of morphological, physiological and operational data, reflecting the operation of an AS system in different experimental conditions. PCA and PLS were used to treat the collected data, integrating image analysis parameters from aggregated and filamentous biomass characterization, biomass composition on Gram-positive/Gram-negative bacteria and viable/damaged bacteria, alongside operational parameters. The potential of PCA was examined for the identification of each condition and PLS was then used to predict several parameters for each condition. Thus, combining QIA with chemometric techniques led to alternative methods to promptly monitor AS systems. Also, Pantsar-Kallio et al. [200] combined PCA with PLS into an effective tool for analyzing and displaying the composition of sewage. This study showed that the pollutants from different sources could be characterized. The nature of sewage pollutants, originating mainly from domestic waste, was carefully studied and found to depend on many factors such as the location of sampling areas, population lifestyle, day of week and sampling time. Singh et al. [201] used chemometric techniques such as cluster analysis (CA), DA, PCA, and PLS to analyze the wastewater dataset and identify the factors which affect domestic sewage composition, spatial and temporal variations, and similarity and/or dissimilarity among wastewater characteristics.

In summary, the application of chemometric techniques to QIA data demands special attention, since these modeling procedures could facilitate the replacement of labor, expensive and time consuming analytical measurements.

\section{Concluding remarks and future perspectives}

Nowadays, microscopy techniques coupled to staining procedures, including the use of fluorescent dyes, as a research tool, are of particular interest due to the high amount of information provided by these techniques. In this way, it is possible to obtain relevant information on the biomass characterization, viability and composition in near real time. However, further research is still needed to relate the microscopic observations with the standard analytical parameters.

This review showed that QIA is considered a powerful technology with great potential of application in wastewater treatment especially in AS systems. Over the years, the number of image analysis studies for biomass and sludge characterization is ever increasing, aiming at clean and safe final effluents in wastewater treatment, through the combination of operating parameters and image analysis information. In AS systems, particularly EBPR systems, image analysis procedures could be a pathway to overcome the lack of information regarding microbial population characterization. Image analysis could also contribute to study microbial diversity in aerobic granular sludge systems, but research is still needed to find the operational parameters effect on microbial population dynamics. Furthermore, the combination of the above techniques with chemometric techniques, such as PCA, PLS, DT, DA and artificial neural networks, has been shown to have great potential in allowing for an early-warning system regarding operating problems detection.

In conclusion, the application of QIA, alongside multivariate statistical analysis, as a monitoring tool has been found to contribute decisively to survey the AS contents and physiology in full-scale WWTPs, minimizing the occurrence of plant malfunctions and helping to propose appropriate correction methodologies, and reducing effluent composition discrepancies.

\section{Acknowledgments}

The authors acknowledge the financial support to Daniela P. Mesquita through the post-doctoral grant (SFRH/BPD/82558/2011) and the project PTDC/EBB-EBI/103147/2008 provided by Fundação para a Ciência e a Tecnologia (Portugal).

\section{References}

[1] Y. Liu, H.P. Fang, Crit. Rev. Env. Sci. Tec. 33 (2003) 237.

[2] B.M. Wilén, B. Jin, P. Lant, Water Res. 37 (2003) 2127.

[3] B.M. Wilén, D. Lumley, A. Mattsson, T. Mino, Water Res. 42 (2008) 4404.

[4] B.M. Wilén, M. Onuki, M. Hermansson, D. Lumley, T. Mino, Water Res. 42 (2008) 2300.

[5] B. Jin, B.M. Wilén, P. Lant, Chem. Eng. J. 95 (2003) 221.

[6] A.L. Amaral, E.C. Ferreira, Anal. Chim. Acta 544 (2005) 246.

[7] A.J. Schuler, H. Jang, Environ. Sci. Technol. 41 (2007) 1675.

[8] A.J. Schuler, H. Jang, Water Res. 41 (2007) 1814.

[9] P.A. Jones, A.J. Schuler, Chem. Eng. J. 164 (2010) 16

[10] P. Madoni, Water Res. 28 (1994) 67.

[11] H. Salvadó, A. Palomo, M. Mas, J. Puigagut, M.P. Gracia, Water Res. 38 (2004) 2571.

[12] D.H. Eikelboom, Process Control of Activated Sludge Plants by Microscopic Investigation, IWA Publishing, London, England, 2000.

[13] D. Jenkins, M.G. Richard, G. Daigger, Manual on the Causes and Control of Activated Sludge Bulking, Foaming and other Solids Separation Problems, Lewis publishing, Boca Raton, FL, USA, 2003.

[14] R.J. Seviour, L.L. Blackall, The Microbiology of Activated Sludge, Kluwer Academic Publishers, USA, 1999.

[15] G. Ziglio, G. Andreottola, S. Barbesti, G. Boschetti, L. Bruni, P. Foladori, R. Villa, Water Res. 36 (2002) 460.

[16] S. Foster, J.R. Snape, H.M. Lappin-Scott, J. Porter, Appl. Environ. Microb. 68 (2002) 4772.

[17] Invitrogen Molecular Probes, LIVE/DEAD ${ }^{\circledR}$ BacLight $^{\mathrm{TM}}$ Bacterial Viability Kits, Manuals and Product Inserts, 2004, http://probes.invitrogen.com/ media/pis/mp07007.pdf

[18] X. Hao, Q. Wang, X. Zhang, Y. Cao, M. van Loosdrecht, Water Res. 43 (2009) 3604.

[19] J.N. Louvet, G. Attik, D. Dumas, O. Potier, M.N. Pons, Int. J. Hyg. Envir. Heal. 214 (2011) 470.

[20] A. Oehmen, P.C. Lemos, G. Carvalho, Z. Yuan, J. Keller, L.L. Blackall, M.A.M. Reis, Water Res. 41 (2007) 2271.

[21] M. Wagner, R. Amann, P. Kämpfer, B. Assmus, A. Hartmann, P. Hutzler, N. Springer, K.H. Schleifer, Syst. Appl. Microbiol. 17 (1994) 405

[22] M. Wagner, G. Rath, H.P. Koops, J. Flood, R. Amann, Water Sci. Technol. 34 (1996) 237.

[23] F.L. de los Reyes, W. Ritter, L. Raskin, Appl. Environ. Microbiol. 63 (1997) 1107.

[24] R. Erhart, D. Bradford, R.J. Seviour, R. Amann, L.L. Blackall, Syst. Appl. Microbiol. 20 (1997) 310.

[25] R.J. Davenport, T.P. Curtis, M. Goodfellow, F.M. Stainsby, M. Bingley, Appl. Environ. Microbiol. 66 (2000) 1158.

[26] M. Schuppler, M. Wagner, G. Schön, U.B. Göbel, Microbiology 144 (1998) 249

[27] T. Kanagawa, Y. Kamagata, S. Aruga, T. Kohno, M. Horn, M. Wagner, Appl. Environ. Microbiol. 66 (2000) 5043.

[28] M. Wagner, A. Loy, R. Nogueira, U. Purkhold, N. Lee, H. Daims, Anton. Leeuw. 81 (2002) 665.

[29] C. Lopez, M.N. Pons, E. Morgenroth, Water Res. 39 (2005) 456.

[30] T. Hug, W. Gujer, H. Siegrist, Water Res. 39 (2005) 3837.

[31] G. Carvalho, P.C. Lemos, A. Oehmen, M.A.M. Reis, Water Res. 41 (2007) 4383.

[32] M. da Motta, M.N. Pons, N. Roche, H. Vivier, Biochem. Eng. J. 9 (2001) 165.

[33] M. da Motta, M.N. Pons, N. Roche, Water Sci. Technol. 43 (2001) 91.

[34] M. da Motta, M.N. Pons, N. Roche, Water Sci. Technol. 46 (2002) 363.

[35] M. da Motta, M.N. Pons, N. Roche, Bioproc. Biosyst. Eng. 25 (2003) 387.

[36] R. Jenné, E.N. Banadda, N. Philips, J.F. Van Impe, J. Environ. Sci. Health A Tox. Hazard. Subst. Environ. Eng. 38 (2003) 2009.

[37] R. Jenné, E.N. Banadda, I.Y. Smets, J.F. Van Impe, Water Sci. Technol. 50 (2004) 281.

[38] R. Jenné, E.N. Banadda, I.Y. Smets, A. Bamelis, L. Verdickt, J.F. Van Impe, Water Sci. Technol. 52 (2005) 193.

[39] M.N. Pons, H. Vivier, Adv. Biochem. Eng. Biotechnol. 60 (1998) 61. 
[40] D.P. Mesquita, O. Dias, A.M.A. Dias, A.L. Amaral, E.C. Ferreira, Anal. Chim. Acta $642(2009) 94$

[41] M.N. Pons, H. Vivier, Adv. Biochem. Eng. Biotechnol. 66 (1999) 133.

[42] D.P. Mesquita, O. Dias, A.L. Amaral, E.C. Ferreira, Bioproc. Biosys. Eng. 32 (2009) 361.

[43] D.P. Mesquita, O. Dias, A.L. Amaral, E.C. Ferreira, Microsc. Microanal. 16(2010) 166.

[44] D.P. Mesquita, O. Dias, R.A.V. Elias, A.L. Amaral, E.C. Ferreira, Microsc. Microanal. 16 (2010) 561.

[45] D.P. Mesquita, A.L. Amaral, E.C. Ferreira, Chemosphere 85 (2011) 643.

[46] D.P. Mesquita, A.L. Amaral, E.C. Ferreira, Anal. Chim. Acta. 705 (2011) 235

[47] P. Teppola, S.P. Mujunen, P. Minkkinen, Chemometr. Intell. Lab. 38 (1997) 197.

[48] C.K. Yoo, P.A. Vanrolleghem, I.B. Lee, J. Biotechnol. 105 (2003) 135-163.

[49] A.C. Avellar, T. Görner, J. Yvon, P. Chappe, P. Guinot-Thomas, P.h. Donato, Water Res. 45 (2011) 981.

[50] A.M.P. Martins, K. Pagilla, J.J. Heijnen, M.C.M. van Loosdrecht, Water Res. 38 (2004) 793.

[51] S. Rossetti, M.C. Tomei, P.H. Nielsen, V. Tandoi, FEMS Microbiol. Rev. 29 (2005) 49.

[52] B.M. Wilén, J.L. Nielsen, K. Keiding, P.H. Nielsen, Colloids Surf. B 18 (2000) 145.

[53] L.H. Mikkelsen, K. Keiding, Water Res. 36 (2002) 2451.

[54] D. Li, J. Ganczarczyk, Environ. Sci. Technol. 23 (1989) 1385.

[55] D. Li, J. Ganczarczyk, Biotechnol. Bioeng. 35 (1990) 57.

[56] D. Li, J. Ganczarczyk, Water Res. 21 (1987) 257.

[57] D. Li, J. Ganczarczyk, J. Water Pollut. Control Fed. 63 (1991) 806.

[58] A. Andreadakis, Water Res. 27 (1993) 1707.

[59] K. Barbusinski, H. Koscielniak, Water Res. 29 (1995) 1703.

[60] K. Grijspeerdt, W. Verstraete, Water Res. 31 (1997) 1126.

[61] X.Y. Li, S.F. Yang, Water Res. 41 (2007) 1022.

[62] B.Q. Liao, I.G. Droppo, G.G. Leppard, S.N. Liss, Water Res. 40 (2006) 2583

[63] V. Urbain, J.C. Block, D.J. Manem, Water Res. 27 (1993) 829.

[64] B. Jin, B.M. Wilén, P. Lant, Chem. Eng. J. 98 (2004) 115.

[65] C.P. Chu, D.J. Lee, Chem. Eng. Sci. 59 (2004) 1875.

[66] M. Sezgin, D. Jenkins, D.S. Parker, J. Water Pollut. Control Fed. 50 (1978) 362.

[67] M. Sezgin, D. Jenkins, J.C. Palm, Prog. Water Technol. 12 (1980) 171

[68] M. Sezgin, Water Res. 16 (1982) 83.

[69] J. Ganczarczyk, Water Sci. Technol. 30 (1994) 87.

[70] P. Jarvis, B. Jefferson, J. Gregory, S.A. Parsons, Water Res. 39 (2005) 3121

[71] K.C. Lindea, E.M. Seviour, R.J. Seviour, L.L. Blackall, J.A. Soddell, Practical methods for the examination and characterization of activated sludge, in: R.J Seviour, L.L. Blackall (Eds.), The Microbiology of Activated Sludge, Kluwer Academic Publishers, London, 1999.

[72] A.M. Saunders, A. Oehmen, L.L. Blackall, Z. Yuan, J. Keller, Water Sci. Technol. 47 (2003) 37.

[73] B.M. Wilén, P. Balmer, Water Res. 33 (1999) 391.

[74] D. Pandolfi, M.N. Pons, Biotechnol. Lett. 26 (2004) 1841.

[75] L.S. Serafim, P.C. Lemos, C. Levantesi, V. Tandoi, H. Santos, M.A.M. Reis, J. Microbiol. Meth. 51 (2002) 1

[76] D. Pandolfi, M.N. Pons, M. da Motta, Biotechnol. Lett. 29 (2007) 1263.

[77] D.P. Mesquita, G. Selvaggio, J.R. Cunha, C.S. Leal, A.L. Amaral, E.C. Ferreira, Lect. Notes Comput. Sci. 7975 (2013) 790

[78] G. Gahrton, Exp. Cell Res. 34 (1964) 488.

[79] G.J.F. Smolders, J. van der Meij, M.C.M. van Loosdrecht, Biotechnol. Bioeng. 43 (1994) 461.

[80] R.I. Amann, B.J. Binder, R.J. Olson, S.W. Chisholm, R. Devereux, D.A. Stahl, Appl. Environ. Microbiol. 56 (1990) 1919.

[81] L.L. Blackall, H. Stratton, D. Bradford, T.D. Dot, C. Sjörup, E.M. Seviour, R.J. Seviour, Int. J. Syst. Evol. Microbiol. 46 (1996) 344.

[82] S. Rossetti, C. Christensson, L.L. Blackall, V. Tandoi, J. Appl. Microbiol. 82 (1997) 405.

[83] L.L. Blackall, E.M. Seviour, D. Bradford, S. Rossetti, V. Tandoi, R.J. Seviour, Int. J. Syst. Evol. Microbiol. 50 (2000) 703.

[84] J.R. Liu, C.A. McKenzie, E.M. Seviour, R.I. Webb, L.L. Blackall, C.P. Saint, R.J. Seviour, Int. J. Syst. Evol. Microbiol. 51 (2001) 195.

[85] E.M. Seviour, K. Eales, L. Izzard, M. Beer, E.L. Carr, R.J. Seviour, Water Sci. Technol. 54 (2006) 47.

[86] A. Oehmen, Z Yuan, L.L. Blackall, J. Keller, Biotechnol. Bioeng. 91 (2005) 162.

[87] A. Oehmen, A.M. Saunders, M.T. Vives, Z. Yuan, J. Keller, J. Biotechnol. 123 (2006) 22.

[88] J.L. Sanz, T. Köchling, Process Biochem. 42 (2007) 119.

[89] R. Manser, K. Muche, W. Gujer, H. Siegrist, Water Res. 39 (2005) 1585.

[90] M. Wagner, M. Horny, H. Daims, Curr. Opin. Microbiol. 6 (2003) 302

[91] Invitrogen Molecular Probes, LIVE BacLight ${ }^{\mathrm{TM}}$ Bacterial Gram Kits, Manuals and Product Inserts, 2001, http://probes.invitrogen.com/media/ pis/mp07008.pdf

[92] L. Boulos, M. Prevost, B. Barbeau, J. Coallier, R. Desjardins, J. Microbiol. Meth. 37 (1999) 77.

[93] J.N. Louvet, Y. Heluin, G. Attik, D. Dumas, O. Potier, M.N. Pons, Process Biochem. 45 (2010) 1787.

[94] Invitrogen Molecular Probes, ViaGram ${ }^{\mathrm{TM}}$ Red+ Bacterial Gram Stain, Manuals and Product Inserts, 2001, http://www.mobitec.com/probes/docs/ media/pis/mp07022.pdf

[95] M. Streichan, J.R. Golecki, G. Schon, FEMS Microbiol. Ecol. 73 (1990) 113.

[96] A.G. Ostel, J.G. Holt, Appl. Environ. Microbiol. 44 (1982) 238.

[97] I.E. Shennawy, D.J. Gee, R.W. Horobin, S.R. Aparicio, Histochemistry 81 (1984) 93.
[98] S. Günther, M. Trutnau, S. Kleinsteuber, G. Hause, T. Bley, I. Roske, H. Harms, S. Muller, Appl. Environ. Microbiol. 75 (2009) 2111.

[99] S. He, A.Z. Gu, K.D. McMahon, Microb. Ecol. 55 (2008) 229.

[100] N. Majed, Y. Li, A.Z. Gu, Curr. Opin. Biotechnol. 23 (2012) 852.

[101] R. Aschar-Sobbi, A.Y. Abramov, C. Diao, M.E. Kargacin, G.J. Kargacin, R.J. French, E. Pavlov, J. Fluoresc. 18 (2008) 859.

[102] A. Kuruda, N. Takiguchi, T. Gotanda, K. Nomura, J. Kato, T. Ikeda, H. Ohtake, Biotechnol. Bioeng. 78 (2002) 333.

[103] M. Kawaharasaki, H. Tanaka, T. Kanagaw, K. Nakamura, Water Res. 33 (1999) 257.

[104] P. Klauth, R.S. Pallerla, D. Vidaurre, C. Ralfs, V.F. Wendisch, S.M. Schoberth, Appl. Microbiol. Biotechnol. 72 (2006) 1099.

[105] D. Betscheider, J. Jose, Anal. Biochem. 384 (2009) 194.

[106] W.T. Mason, Fluorescent and Luminescent Probes for Biological Activity: a Practical Guide to Technology for Quantitative Real-time Analysis, Academic Press, San Diego, CA, USA, 1999

[107] D.P. Mesquita, C. Leal, J.R. Cunha, A. Oehmen, A.L. Amaral, M.A.M. Reis, E.C. Ferreira, Anal. Chim. Acta 770 (2013) 36

[108] H. Daims, M. Wagner, Appl. Microbiol. Biotechnol. 75 (2007) 237.

[109] H. Daims, N.B. Ramsing, K.H. Schleifer, M. Wagner, Appl. Environ. Microbiol 37 (2001) 5810

[110] M. Schmid, A. Thill, U. Purkhold, M. Walcher, J.Y. Bottero, P. Ginestet, P.H. Nielsen, S. Wuertz, M. Wagner, Water Res. 37 (2003) 2043.

[111] P. Larsen, J.L. Nielsen, D. Otsen, P.H. Nielsen, Appl. Environ. Microbiol. 74 (2008) 1517.

[112] P.H. Nielsen, H. Daims, H. Lemmer, FISH Handbook for Biological Wastewater Treatment: Identification and Quantification of Microorganisms in Activated Sludge and Biofilms by FISH, IWA Publishing, London, UK, 2009.

[113] H.Y. Chung, D.J. Lee, J. Colloid Interf. Sci. 267 (2003) 136

[114] C.P. Chu, D.G. Tsai, D.J. Lee, J.H. Tay, J. Environ. Manage. 76 (2005) 239.

[115] S. Szilveszter, B. Ráduly, S. Bucs, B. Ábrahán, S. Lányi, D.N. Robescu, Environ. Eng. Manag. J. 11 (2012) 669.

[116] S. Szilveszter, B. Ráduly, B. Ábrahán, S. Lányi, J. Chem. Technol. Biotechnol. 88 (2012) 1295.

[117] A.E. Dixon, S. Damaskinos, A. Ribes, E. Seto, M.C. Beland, T. Uesaka, B.E Dalrymple, S.P. Duttagupta, P.M. Fauchet, Confocal scanning beam laser microscope/macroscope: applications requiring large data sets, Proc. SPIE Three-Dimensional Microscopy: Image Acquisition and Processing II 2412 (1995) 12.

[118] H. Daims, S. Lücker, M. Wagner, Environ. Microbiol. 8 (2006) 200

[119] A. Blum, I. Zalaudek, G. Argenziano, Semin. Cutan. Med. Surg. 27 (2008) 11.

[120] A.C.A. Marijnissen, K.L. Vincken, P.A.J.M. Vos, D.B.F. Saris, M.A. Viergever, J.W.J Bijlsma, L.W. Bartels, F.P.J.G. Lafeber, Osteoarthr. Cartilage 16 (2008) 234.

[121] M. Bould, S. Barnard, I.D. Learmonth, J.L. Cunningham, J.R.W. Hardy, Clin. Biomech. 14 (1999) 434.

[122] A. Das, C.C. Nguyen, F. Li, B. Li, Gastrointest. Endosc. 67 (2008) 861.

[123] M.R. Vaughn, R.A.H. van Oorschot, S. Baindur-Hudson, Forensic Sci. Int. 183 (2009) 97.

[124] D.K. Berner, L.K. Paxson, Biol. Control 28 (2003) 171

[125] D.B. Patankar, T.C. Liu, T. Oolman, Biotechnol. Bioeng. 42 (1993) 571.

[126] M.N. Pons, H. Vivier, J.F. Rémy, J.A. Dodds, Biotechnol. Bioeng. 42 (1993) 1352.

[127] F.M. Kawasse, P.F. Amaral, M.H.M. Rocha-Leão, A.L. Amaral, E.C. Ferreira, M.A.Z. Coelho, Bioproc. Biosyst. Eng. 25 (2003) 371.

[128] M.A.Z. Coelho, I. Belo, R. Pinheiro, A.L. Amaral, M. Mota, J.A.P. Coutinho, E.C. Ferreira, Appl. Microbiol. Biot. 66 (2004) 318.

[129] M.A.Z. Coelho, J.A.P. Coutinho, E.C. Ferreira, M. Mota, I. Belo, Process Biochem 42 (2007) 1378

[130] S. Carneiro, A.L. Amaral, A.C.A. Veloso, T. Dias, A.M. Peres, E.C. Ferreira, I. Rocha, Biotechnol. Progr. 25 (2009) 882.

[131] A.W. David, J.H. Paul, J. Microbiol. Meth. 9 (1989) 257.

[132] M. Morrin, O.P. Ward, Mycol. Res. 92 (1989) 265.

[133] M.N. Pons, A. Wagner, H. Vivier, A. Marc, Biotechnol. Bioeng. 40 (1992) 187.

[134] J.C. Russ, The Image Processing Handbook, fourth ed., CRC Press, Boca Raton, 2002.

[135] A.L. Amaral, 2003. Image analysis in biotechnological processes: applications to wastewater treatment, PhD Thesis, University of Minho, Braga, Portugal http://hdl.handle.net/1822/4506

[136] C.A. Gross, C.K. Reddy, F.B. Dazzo, Microb. Ecol. 59 (2010) 400.

[137] D. Snidaro, F. Zartarian, E. Jorand, J.Y. Bottero, J.C. Block, J. Manem, Water Sci. Technol. 36 (1997) 313.

[138] Q. Jiang, B.E. Logan, Environ. Sci. Technol. 25 (1991) 2031.

[139] X. Li, R.P.C. Leung, Environ. Sci. Technol. 39 (2005) 2731.

[140] D.P. Mesquita, 2011. Image analysis and chemometric techniques as monitoring tools to characterize aggregated and filamentous organisms in activated sludge processes, PhD Thesis, University of Minho, Braga, Portugal, http://hdl.handle.net/1822/12470

[141] A.L. Amaral, D.P. Mesquita, E.C. Ferreira, Chemosphere 91 (2013) 705

[142] J.N. Louvet, C. Giammarino, O. Potier, M.N. Pons, Environ. Pollut. 158 (2010) 688.

[143] M. da Motta, A.L. Amaral, L. Neves, P. Araya-Koff, E.C. Ferreira, M.M. Alves, M Mota, N. Roche, H. Vivier, M.N. Pons, Dilution effects on biomass characterization by image analysis, in: Proceedings of the 14th Brazilian Congress on Chemical Engineering, Natal, Brazil, 2002, p. 9 (CD-ROM).

[144] E. Liwarska-Bizukojc, M. Bizukojc, Process Biochem. 40 (2005) 2067.

[145] R. Jenné, C. Cenens, A.H. Geeraerd, J.F. Van Impe, Biotechnol. Lett. 24 (2002) 931. 
[146] E.N. Banadda, I.Y. Smets, R. Jenné, J.F. Van Impe, Bioproc. Biosyst. Eng. 27 (2005) 339.

[147] R. Jenné, E.N. Banadda, G. Gins, J. Deurinck, I.Y. Smets, A.H. Geeraerd, J.F. Van Impe, Water Sci. Technol. 54 (2006) 167.

[148] R. Jenné, E.N. Banadda, I.Y. Smets, J. Deurinck, J.F. Van Impe, Microsc. Microanal. 13 (2007) 36.

[149] Y.P. Perez, S.G.F. Leite, M.A.Z. Coelho, Braz. J. Chem. Eng. 23 (2006) 319.

[150] R. Govoreanu, K. Vandegehuchte, H. Saveyn, I. Nopens, B. De Clercq, P. van der Meeren, P. Vanrolleghem, Med. Fac. Landbouww Univ. Gent 67 (2002) 75.

[151] A. Thill, S. Veerapaneni, B. Simon, M. Wiesner, J.Y. Bottero, D. Snidaro, J. Colloid Interf. Sci. 204 (1998) 357.

[152] A. Arelli, L. Luccarini, P. Madoni, Water Sci. Technol. 59 (2009) 2029.

[153] D.P. Mesquita, O. Dias, A.L. Amaral, E.C. Ferreira, M.A.Z. Coelho, J. Chem. Technol. Biotechnol. 84 (2009) 554.

[154] D.P. Mesquita, R.R. Ribeiro, A.L. Amaral, E.C. Ferreira, M.A.Z. Coelho, Environ. Sci. Pollut. R. 18 (2011) 1390.

[155] E. Liwarska-Bizukojc, M. Bizukojc, Enzyme Microb. Tech. 39 (2006) 660

[156] E. Liwarska-Bizukojc, M. Bizukojc, Enzyme Microb. Tech. 41 (2007) 26.

[157] Y.P. Ginoris, A.L. Amaral, A. Nicolau, M.A.Z. Coelho, E.C. Ferreira, Water Res. 41 (2007) 2581.

[158] C. Cenens, K.P. Van Beurden, R. Jenné, J.F. Van Impe, Water Sci. Technol. 46 (2002) 381.

[159] C. Cenens, R. Jenné, J.F. Van Impe, Water Sci.Technol. 45 (2002) 85.

[160] M. Casellas, C. Dagot, M.N. Pons, G. Guibaud, N. Tixier, M. Baudu, Biochem. Eng. J. 21 (2004) 171.

[161] C. Dagot, M.N. Pons, M. Casellas, G. Guibaud, P. Dollet, M. Baudu, Water Sci. Technol. 43 (2001) 27

[162] E.M. Contreras, L. Giannuzzi, N.E. Zaritzky, Water Res. 38 (2004) 2621.

[163] I.Y. Smets, E.N. Banadda, J. Deurinck, N. Renders, R. Jenné, J.F. Van Impe, J. Process Contr. 16 (2006) 313.

[164] R. Van den Broeck, J.F. Van Impe, I.Y. Smets, J. Biotechnol. 141 (2009) 147.

[165] J. Van Dierdonck, R. Van den Broeck, E. Vervoort, P. D'haeninck, D. Springael, J. Van Impe, I. Smets, Process Biochem. 47 (2012) 2227.

[166] R. Van den Broeck, J. Van Dierdonck, B. Caerts, I. Bisson, B. Kregersman, P. Nijskens, C. Dotremont, J. Van Impe, I.Y. Smets, Sep. Purif. Technol. 71 (2010) 279.

[167] R. Van den Broeck, P. Krzeminski, J. Van Dierdonck, G. Gins, M. LousadaFerreira, J. Van Impe, J.H.J.M. van der Graaf, I.Y. Smets, J.B. van Lier, J. Membr. Sci. 378 (2011) 330.

[168] R. Van den Broeck, J. Van Dierdonck, P. Nijskens, C. Dotremont, P. Krzeminski, J.H.J.M. van der Graaf, J.B. van Lier, J. Van Impe, I.Y. Smets, J. Membr. Sci. 401-402 (2012) 48.

[169] T. Stalder, M. Alrhmoun, J.N. Louvet, M. Casellas, C. Maftah, C. Carrion, M.N. Pons, O. Pahl, M.C. Ploy, C. Dagot, Environ. Sci. Technol. 47 (2013) 7909.

[170] J.L. Nielsen, D. Christensen, M. Kloppenborg, P.H. Nielsen, Environ. Microbiol. 5 (2003) 202.

[171] J.L. Nielsen, S. Juretschko, M. Wagner, P.H. Nielsen, Appl. Environ. Microbiol. 68 (2002) 4629.
[172] C.E. Miller, Chemometrics in process analytical chemistry, in: A. Bakeev (Ed.), Process Analytical Technology, Blackwell Publishing, Oxford, UK, 2005.

[173] J.W. Einax, H.W. Zwanziger, S. Geiss, Chemometrics in Environmental Analysis, VCH, Weinheim, Germany, 1997.

[174] D.S. Lee, M.W. Lee, S.H. Woo, Y.J. Kim, J.M. Park, Process Biochem. 41 (2006) 2050.

[175] S. Mas, A. de Juan, R. Tauler, A. Olivieri, G. Escandar, Talanta 80 (2010) 1052.

[176] D. Lee, P.A. Vanrolleghem, Biotechnol. Bioeng. 82 (2003) 489.

[177] J.A. Baeza, D. Gabriel, J. Lafuente, Water Sci. Technol. 45 (2002) 19.

[178] A.L. Amaral, C. Baptiste, M.N. Pons, A. Nicolau, N. Lima, E.C. Ferreira, M. Mota, H. Vivier, Biotechnol. Tech. 13 (1999) 111

[179] A.L. Amaral, M. da Motta, M.N. Pons, H. Vivier, M. Mota, E.C. Ferreira, Environmetrics 15 (2004) 381.

[180] A.L. Amaral, Y.P. Ginoris, A. Nicolau, M.A.Z. Coelho, E.C. Ferreira, Anal. Bioanal. Chem. 391 (2008) 1321.

[181] Y.P. Ginoris, A.L. Amaral, A. Nicolau, M.A.Z. Coelho, E.C. Ferreira, J. Chemometr 21 (2007) 156.

[182] Y.P. Ginoris, A.L. Amaral, A. Nicolau, M.A.Z. Coelho, E.C. Ferreira, Anal. Chim Acta 595 (2007) 160.

[183] K.V. Gernaey, M.C.M. van Loosdrecht, M. Henze, M. Lind, S.B. Jørgensen, Environ. Modell. Softw. 19 (2004) 763.

[184] B.R. Bakshi, AIChE J. 44 (1998) 1596.

[185] C. Rosen, G. Olsson, Water Sci. Technol. 37 (1998) 197.

[186] R.K. Tomita, S.W. Park, O.A.Z. Stomayor, Chem. Eng. J. 90 (2002) 283.

[187] S.W. Choi, I.B. Lee, Chem. Eng. Sci. 59 (2004) 5897.

[188] J.M. Lee, C. Yoo, I.B. Lee, J. Process Contr. 14 (2004) 467.

[189] T.S. Moon, Y.J. Kim, J.R. Kim, J.H. Cha, D.H. Kim, C.W. Kim, J. Environ. Manage. 90 (2009) 772

[190] D. Aguado, C. Rosen, Eng. Appl. Artif. Intel. 21 (2008) 1080.

[191] P. Principi, F. Villa, M. Bernasconi, E. Zanardini, Water Res. 40 (2006) 99.

[192] A.M.A. Dias, I. Moita, R. Páscoa, M.M. Alves, J.A. Lopes, E.C. Ferreira, Water Sci. Technol. 57 (2008) 1643.

[193] N.D. Lourenço, C.L. Chaves, J.M. Novais, J.C. Menezes, H.M. Pinheiro, D. Diniz, Chemosphere 65 (2006) 786.

[194] N.D. Lourenço, F. Paixão, H.M. Pinheiro, A. Sousa, Appl. Spectrosc. 64 (2010) 1061.

[195] P. Teppola, S.P. Mujunen, P. Minkkinen, Chemometr. Intell. Lab. 41 (1998) 95

[196] A. Ferrer, D. Aguado, S. Vidal-Puig, M. Prats, M. Zarzo, Appl. Stoch. Model. Bus. 24 (2008) 551

[197] S.P. Mujunen, P. Minkkinen, P. Teppola, R.S. Wirkkala, Chemometr. Intell. Lab. 41 (1998) 83.

[198] M.C. Sarraguça, A. Paulo, M.M. Alves, A.M.A. Dias, J.A. Lopes, E.C. Ferreira, Anal Bioanal. Chem. 395 (2009) 1159.

[199] N.D. Lourenço, J.C. Menezes, H.M. Pinheiro, D. Diniz, Environ. Technol. 29 (2008) 891.

[200] M. Pantsar-Kallio, S.P. Mujunen, G. Hatzimihalis, P. Koutoufides, P. Minkkinen, P.J. Wilkie, M.A. Connor, Anal. Chim. Acta 393 (1999) 181.

[201] K.P. Singh, A. Malik, D. Mohan, S. Sinha, V.K. Singh, Anal. Chim. Acta 532 (2005) 